\title{
High Bypass Ratio Jet Noise Reduction and Installation Effects Including Shielding Effectiveness
}

\author{
Russell H. Thomas* \\ NASA Langley Research Center, Hampton, VA 23681 USA \\ Michael J. Czech ${ }^{\dagger}$ \\ The Boeing Company, Everett, WA 98204 USA \\ and \\ Michael J. Doty \\ NASA Langley Research Center, Hampton, VA 23681 USA
}

\begin{abstract}
An experimental investigation was performed to study the propulsion airframe aeroacoustic installation effects of a separate flow jet nozzle with a Hybrid Wing Body aircraft configuration where the engine is installed above the wing. Prior understanding of the jet noise shielding effectiveness was extended to a bypass ratio ten application as a function of nozzle configuration, chevron type, axial spacing, and installation effects from additional airframe components. Chevron types included fan chevrons that are uniform circumferentially around the fan nozzle and $T$-fan type chevrons that are asymmetrical circumferentially. In isolated testing without a pylon, uniform chevrons compared to $T$-fan chevrons showed slightly more low frequency reduction offset by more high frequency increase. Phased array localization shows that at this bypass ratio chevrons still move peak jet noise source locations upstream but not to nearly the extent, as a function of frequency, as for lower bypass ratio jets. For baseline nozzles without chevrons, the basic pylon effect has been greatly reduced compared to that seen for lower bypass ratio jets. Compared to $T$ fan chevrons without a pylon, the combination with a standard pylon results in more high frequency noise increase and an overall higher noise level. Shielded by an airframe surface 2.17 fan diameters from nozzle to airframe trailing edge, the T-fan chevron nozzle can produce reductions in jet noise of as much as $8 \mathrm{~dB}$ at high frequencies and upstream angles. Noise reduction from shielding decreases with decreasing frequency and with increasing angle from the jet inlet. Beyond an angle of 130 degrees there is almost no noise reduction from shielding. Increasing chevron immersion more than what is already an aggressive design is not advantageous for noise reduction. The addition of airframe control surfaces, including vertical stabilizers and elevon deflection, showed only a small overall impact. Based on the test results, the best overall nozzle configuration design was selected for application to the N2A Hybrid Wing Body concept that will be the subject of the NASA Langley 14 by 22 Foot Subsonic Tunnel high fidelity aeroacoustic characterization experiment. The best overall nozzle selected includes T-fan type chevrons, uniform chevrons on the core nozzle, and no additional pylon of the type that created a strong acoustic effect at lower bypass ratios. The T-fan chevrons are oriented azimuthally away from the ground observer locations. This best overall nozzle compared to the baseline nozzle was assessed, at equal thrust, to produce sufficient installed noise reduction of the jet noise component to enable the N2A HWB to meet NASA's noise goal of $42 \mathrm{~dB}$ cumulative below Stage 4.
\end{abstract}

\footnotetext{
* Senior Research Engineer, Aeroacoustics Branch, MS 461, AIAA Senior Member, Russell.H.Thomas@NASA.gov

${ }^{\dagger}$ Aeroacoustics Engineer, Boeing Commercial Airplanes, AIAA Member, Michael.J.Czech@ Boeing.com

${ }^{*}$ Research Engineer, Aeroacoustics Branch, MS 461, AIAA Senior Member, Michael.J.Doty@NASA.gov
} 


\section{Nomenclature}

$\begin{array}{ll}B P R & =\text { bypass ratio } \\ C J E S & =\text { Compact Jet Engine Simulator } \\ d B & =\text { decibel } \\ D & =\text { fan nozzle diameter } \\ E P N L & =\text { effective perceived noise level, decibels } \\ f & =\text { frequency }(\mathrm{Hz}) \\ H B P R & =\text { high bypass ratio } \\ H W B & =\text { Hybrid Wing Body, generic term } \\ L B P R & =\text { low bypass ratio } \\ L S A F & =\text { Low Speed Aeroacoustic Facility, Boeing } \\ M_{T} & =\text { Wind Tunnel Mach Number } \\ N P R_{p} & =\text { nozzle pressure ratio of the primary core stream } \\ N P R_{s} & =\text { nozzle pressure ratio of the secondary fan stream } \\ P A A & =\text { Propulsion Airframe Aeroacoustics } \\ S P L & =\text { sound pressure level } \\ T T R_{p} & =\text { total temperature ratio of the primary core stream } \\ T T R_{s} & =\text { total temperature ratio of the secondary fan stream } \\ \theta & =\text { polar directivity angle, degrees, jet axis at } 180 \text { degrees } \\ \psi & =\text { azimuthal directivity angle, degrees }\end{array}$

\section{Introduction}

$\mathrm{P}$ rogress in noise reduction at the aircraft system level is increasingly challenging in terms of both the technical difficulty as well as the cost of discovering and developing new noise reduction technologies. While production aircraft meet current certification requirements, the combination of the strong trends of continued growth in air traffic, increased priority of environmental goals, and the additional limitations imposed by existing airports, such as curfews, results in continued motivation for aircraft noise reduction technology implementation. This leads to the question of the prospects for new technology that could enable the step change in noise reduction called for in NASA's Environmentally Responsible Aviation (ERA) project: 42 EPNdB cumulative below the Stage 4 certification level with a timeframe of 2020 for readiness of key technologies ${ }^{1}$.

This goal is very aggressive and amplifies the need to study configurations where propulsion airframe aeroacoustic installation effects, in particular effective shielding, can be exploited as a significant technology for noise reduction ${ }^{2}$. Propulsion airframe aeroacoustic installation effects may be defined as the noise sources that are created or modified when the engine is integrated with the airframe. The Hybrid Wing Body (HWB) aircraft concept is a candidate configuration under study by the ERA project and represents an unconventional aircraft concept that introduces the fundamental change of installing the engines on top of the airframe. This configuration offers both great challenges and opportunities in terms of the propulsion airframe aeroacoustic installation effects. Community noise reduction is possible through simple shielding, technology that increases the effectiveness of a given shield, as well as fundamental changes in the high lift system.

NASA established the $42 \mathrm{~dB}$ goal in 2007 based in large part on the assumption that technology could be developed to move peak jet noise sources upstream to the nozzle exit for more effective shielding. NASA and industry had already developed considerable experience that gave NASA the confidence that this key assumption could be realized. This understanding had been developed through a series of extensive experimental and computational studies beginning in 2002 through 2005 on the fundamental effects of jet noise reduction and jet noise source re-distribution with chevron and pylon effects ${ }^{3-11}$. Building on this information by 2009, ERA had already developed a technical path for an HWB concept to reach the noise goal. The framework of this study used a GE90like engine because the noise source breakdown of the GE90-like engine was well understood and the necessary reference information was available among other reasons. Czech, Thomas, and Elkoby ${ }^{12}$ conducted an experiment primarily to develop the nozzle and pylon configuration technology for effective shielding of the key jet noise component. Jet noise sources are distributed over many nozzle diameters downstream and are, therefore, considered the most difficult to reduce through shielding. The data were used directly in the system noise assessment of Thomas, Burley, and Olson ${ }^{13}$ that determined this HWB concept could meet the $42 \mathrm{~dB}$ aircraft system noise goal. This was the first HWB aircraft system noise study where high quality, large-scale experimental acoustic data including installation effects were used directly in the system noise assessment process. This study concluded that 
the noise goal was possible given an HWB aircraft concept using near term technologies such as chevrons with the additional acoustic effect of the pylon, advanced acoustic liners, and landing gear noise reduction fairings, together with a lower approach speed and the engines installed two fan nozzle diameters upstream of the trailing edge.

For a further step in development, NASA contracted with Boeing Research and Technology for the design of an HWB concept to meet a $25 \%$ fuel burn goal (relative to existing 737/CFM56 aircraft) simultaneously with a $42 \mathrm{~dB}$ cumulative system noise goal relative to the FAA's Stage 4 level. The resulting concept is shown in Figure 1 and, at full scale, would have a span of $213 \mathrm{ft}$, a gross takeoff weight of 471,600 lbs, a payload of 103,000 lbs, and two BPR 10 turbofan engines, each with 70,000 lbs of thrust (static sea level thrust) and a 1.6 fan pressure ratio. A high fidelity wind tunnel model has been built and tested at NASA Langley's 14 by 22 Foot Subsonic Wind Tunnel for low speed aerodynamic performance by Gatlin, Vicroy and Carter $^{14}$ and is to be tested for its aeroacoustic characteristics starting late in 2012 in the aeroacoustic configuration of the same wind tunnel. While incorporating some of the same key features for noise reduction as the study of Thomas, Burley, and Olson ${ }^{13}$, such as the placement of the engines at least two engine diameters upstream of the trailing edge, this concept also specified an engine of a bypass ratio 10 compared to the bypass ratio 7 of the GE90-like engine from the earlier study ${ }^{13}$.

For high fidelity aeroacoustic assessment, the HWB aircraft of Figure 1, identified as the N2A, will require an advanced nozzle configuration that can sufficiently reduce the jet noise component through both source reduction and shielding effectiveness for this HWB concept to reach the aircraft system level goal of $42 \mathrm{~dB}$ cumulative below Stage 4. Furthermore, the nozzle performance should be equivalent to the baseline, conventional nozzle. The earlier work by Czech, Thomas, and Elkoby ${ }^{12}$ included nozzles of bypass ratio 4.5 and 7 ; however, a bypass ratio 10 nozzle requires extending the knowledge acquired in the earlier work and producing a specific design to meet the goal. This paper documents the process of nozzle concept development, performance assessment, isolated nozzle acoustics, and installed nozzle assessment resulting in the selection of the best overall nozzle. The work in this study will be performed at a $6.2 \%$ scale factor. A copy of this best overall nozzle, but at $5.8 \%$ scale, will then be used in the upcoming NASA ERA sponsored 14 by 22 Foot Subsonic Tunnel high fidelity aeroacoustic test of a wind tunnel model of the N2A concept that is shown in Figure 1.

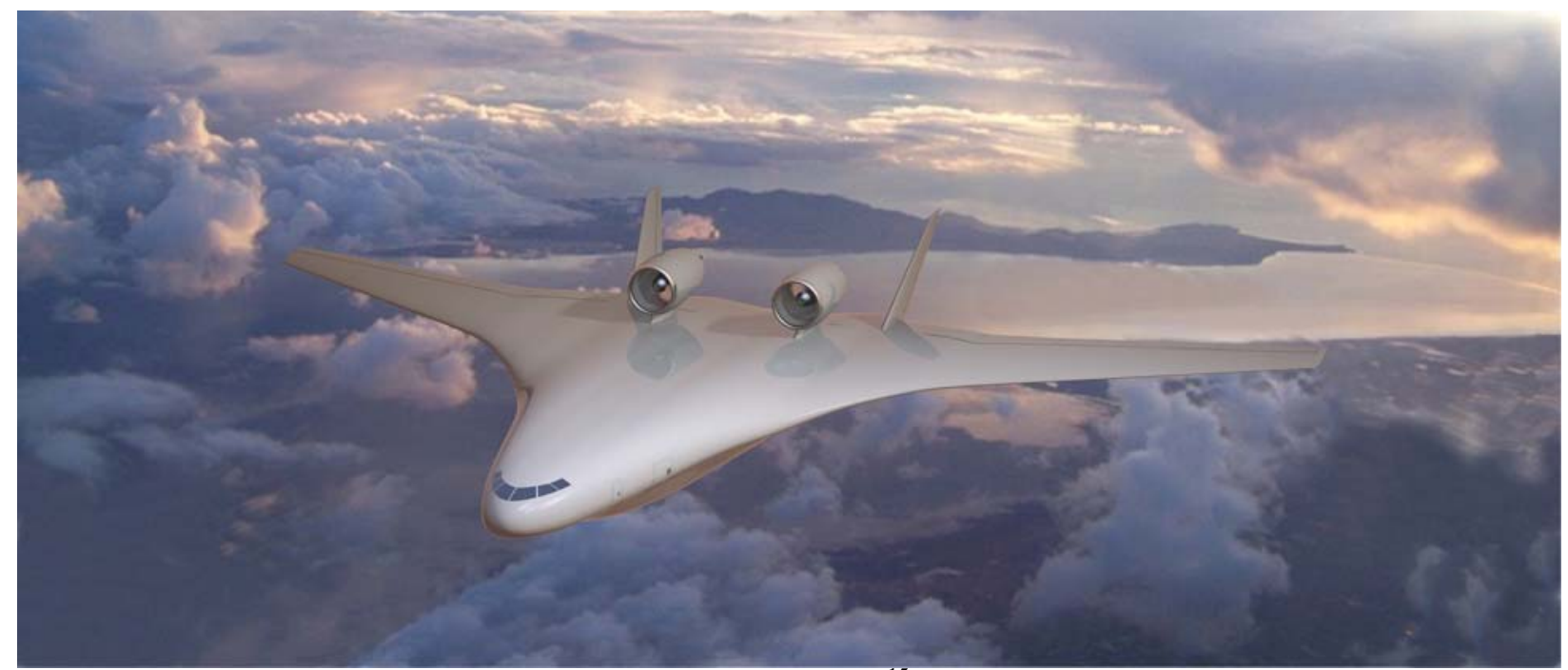

Figure 1. Boeing artist rendering of the Efficient Low Noise $\mathrm{HWB}^{15}(\mathrm{~N} 2 \mathrm{~A})$ aircraft freighter concept designed by Boeing Research and Technology to meet simultaneous goals of $25 \%$ fuel burn reduction compared to a present day aircraft and $42 \mathrm{~dB}$ cumulative noise reduction below Stage 4 .

\section{Experimental Description}

\section{A. Background and Objectives}

The overall objective of the work described in this paper is to design the best overall nozzle for the bypass ratio 10 engine cycle of the HWB N2A aircraft concept.

To accomplish the overall objective requires that the prior work of Czech, Thomas, and Elkoby ${ }^{12}$ with nozzle configurations at bypass ratios of 4.5 and 7 of the GE90-like cycle be extended to the higher bypass ratio of 10. In the prior work, the addition of a conventional type pylon yielded significant spectral changes lowering jet noise by 
up to $4 \mathrm{~dB}$ at downstream polar angles and increasing it by 2 to $3 \mathrm{~dB}$ at forward angles. In addition, the pylon also had a strong azimuthal re-distribution effect on the noise sources. Installations at two fan diameters upstream of the wing trailing edge provided shielding in the forward arc at high frequencies for both the axisymmetric and a conventional round nozzle with pylon. This was consistent with the phased array measurements suggesting that the high frequency sources are predominantly located near the nozzle exit and, consequently, are amenable to shielding. The mid to low frequency sources were observed further downstream and shielding reductions were much less.

Chevrons were designed and used to impact the distribution of sources with the more aggressive design that shows a significant upstream migration of the peak sources in the mid frequency range. Furthermore, the chevrons reduced the low frequency source levels and the typical high frequency increase due to the application of chevron nozzles was successfully shielded because this source was near the nozzle exit plane. Chevrons designed for shielding applications must be more aggressive, immersed further into the flow than otherwise allowable for an unshielded application. Both chevron designs used were of the T-fan ${ }^{9}$ type due to their prior success in conventional, unshielded applications. The pylon was further modified with a new technology that injects air through the shelf of the pylon thus controlling the trajectory and mixing between the core and fan streams. This shelf air injection, or active pylon technology, was effective in reducing low frequency noise and moving jet noise sources closer to the nozzle exit. In general, shielding effectiveness varied as a function of cycle condition with the cutback condition producing higher shielding reductions compared to those at sideline power. This result was consistent with the general migration of noise sources upstream as power condition is lowered, a result important for higher bypass ratio application. Finally, the nozzle configuration with a more strongly immersed chevron and the conventional pylon oriented opposite to the ground observers (not used to attach engine to airframe) produced the largest overall reduction in jet noise including source and shielding effects combined. This nozzle configuration was selected as best for the bypass ratio 7 application to the GE90-like engine and HWB system noise assessment of Thomas, Burley and Olson ${ }^{13}$. In addition, the vertical and elevon airframe control surfaces had small effects and were also documented and assessed in the system noise results ${ }^{12,13}$.

To accomplish the overall objective for the current study, supporting objectives included obtaining information on the following effects at the higher bypass ratio of 10 :

- Basic jet noise shielding characteristics as a function of cycle,

- Pylon effect as a function of presence of the pylon,

- Chevron effect with and without the pylon,

- Airframe control surface effects on shielding,

- Assessing nozzle configurations including the above effects to maximize jet noise shielding effectiveness.

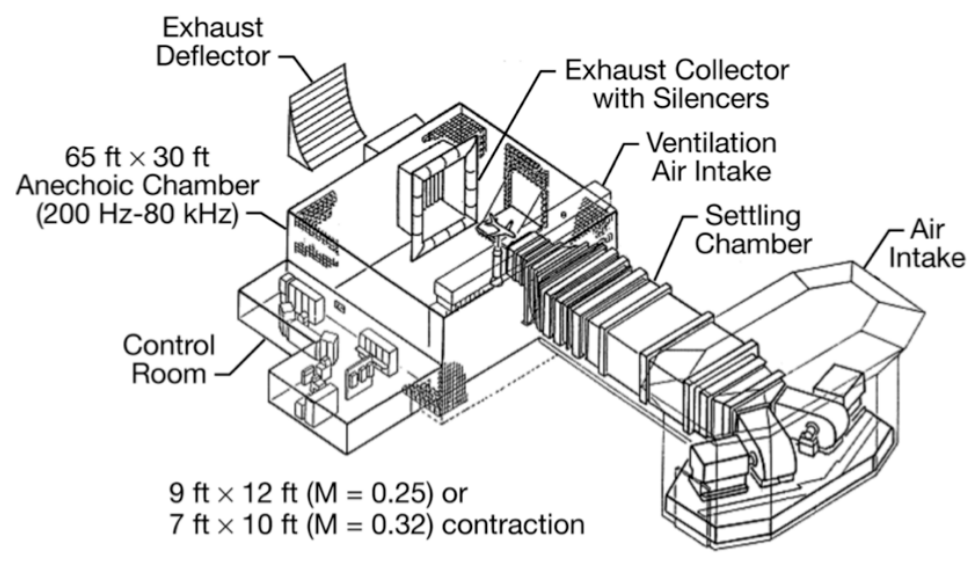

\section{B. Facility Description}

The experimental facility used was the Boeing Low Speed Aeroacoustic

Figure 2. Schematic of the Low Speed Aeroacoustic Facility (LSAF) of The Boeing Company.

Facility (LSAF) shown schematically in Figure 2. The experimental phase of this nozzle configuration research was conducted in late 2011 in order to complete the selection, based on the LSAF test results, of the best overall nozzle to then be used in the subsequent 14 by 22 Foot Subsonic Tunnel HWB aeroacoustic test.

The LSAF was configured with a 9 by 12 foot open jet test section and simultaneous measurements of thrust and noise were conducted. Free-field Brüel \& Kjær Type 4939 microphones were set up to measure a polar angle range from 50 to 150 degrees from the engine inlet axis. Three different arrays of far-field microphones were deployed simultaneously to also measure the azimuthal variation of the sound field at angles of 90, 60 and 30 degrees. It should be noted that the 0 degree azimuth is at the bottom of the jet engine simulator, and the top or crown of the nozzle system is located at 270 degrees in this convention. The array at 90 degrees was laid out in a polar arc at radius $(\mathrm{R})$ of $25 \mathrm{ft}$ and has 16 microphones in increments of 10 degrees from 50 to 100 degrees of polar angle and then in increments of 5 degrees out to a polar angle of 150 degrees. This provided an R/D ratio of about 45 with $\mathrm{D}$ representing the fan nozzle diameter. The array at 90 degrees corresponds to an observer directly underneath an 
aircraft in flyover. The 60 and 30-degree azimuthal sideline arrays were at a distance of $20.1 \mathrm{ft}$ and $14.8 \mathrm{ft}$ respectively.

A photograph of the overall LSAF set-up is shown in Figure 3. A schematic representation of the model set-up in LSAF is also shown in Figure 4, a top view in Figure 4a, and an upstream view in Figure 4b. For configurations including a conventional pylon, this study focused just on the pylon at the 270 degree orientation because the prior study had already identified this as the most favorable orientation for noise reduction using a conventional pylon with its strong acoustic effect. Figure $4 \mathrm{c}$ defines the coordinate convention for the key parameter of axial spacing of the nozzle exit plane relative to the airframe's trailing edge. The spacing of the nozzle relative to the airframe is normalized by the fan nozzle diameter of $\mathrm{D}=6.63$ inches. For the vertical spacing, Y/D is the non-dimensional distance of the nozzle centerline to the trailing edge. For the axial spacing, the non-dimensional X/D values are the locations of the core nozzle exit plane relative to the trailing edge with the core nozzle exit plane being 2.03 inches downstream of the fan exit plane. Positive X/D are locations where the nozzle is upstream of the trailing edge and the jet is, at least, partially shielded. The results of Thomas, Burley and Olson ${ }^{13}$ used the location of $\mathrm{X} / \mathrm{D}=2$. For this study, the nominal design location corresponds to $\mathrm{X} / \mathrm{D}=2.17$.

An HWB planform airframe model was installed from above the test section on an overhead structure that could traverse the airframe in two dimensions in a plane normal to the airframe model as shown in a close up photograph

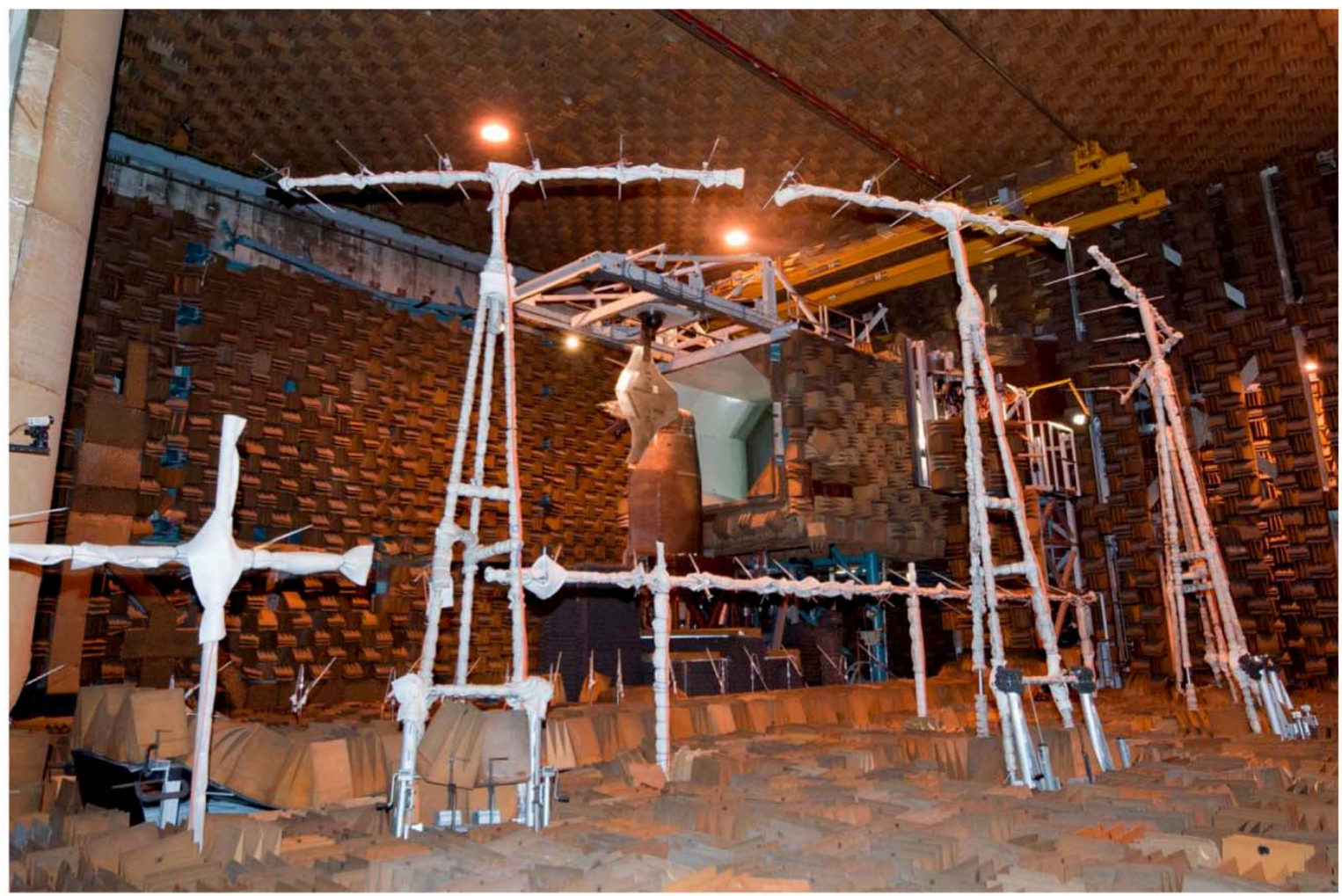

Figure 3. Boeing Low Speed Aeroacoustic Facility Experimental Set-up for HWB installed jet noise testing (November 2011).

in Figure 5. This arrangement allowed easy and remote movement of the airframe model in an axial direction, as well as permitting the engine height above the airframe to be varied. Movements of the airframe in the spanwise direction could only be done manually. While axial spacing is the most important parameter for shielding, vertical spacing could be important in some applications. 


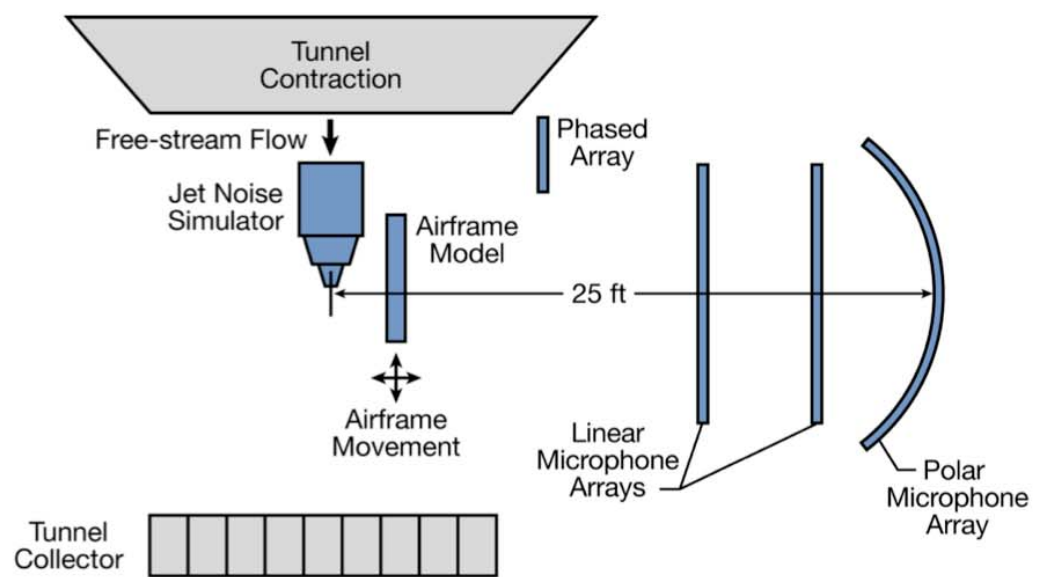

(a) Top View.

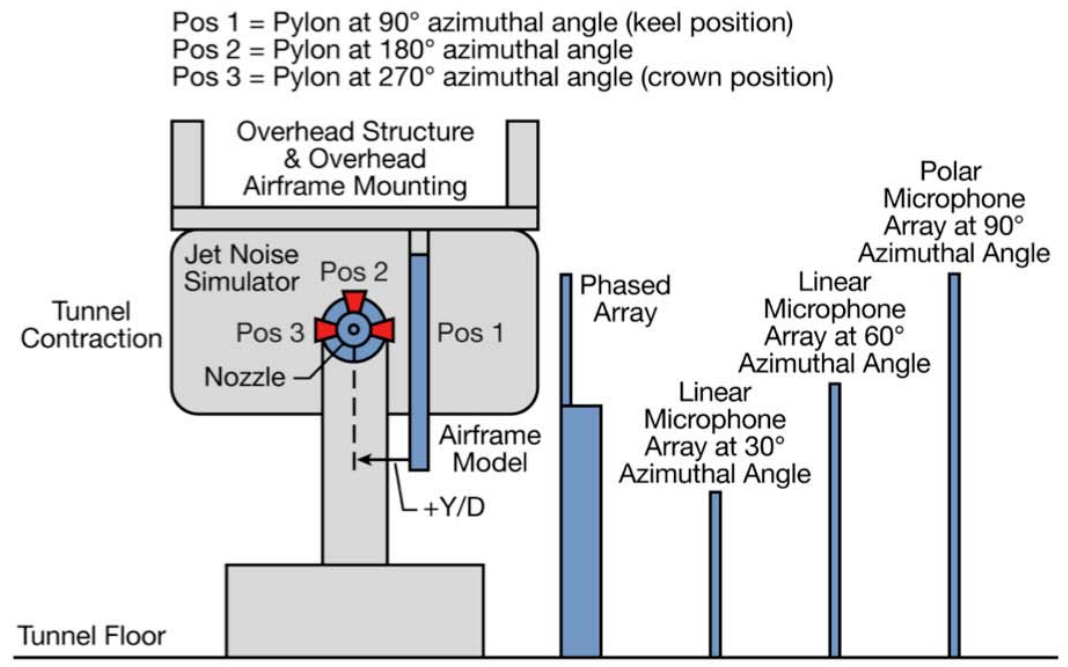

(b) View Looking Upstream.

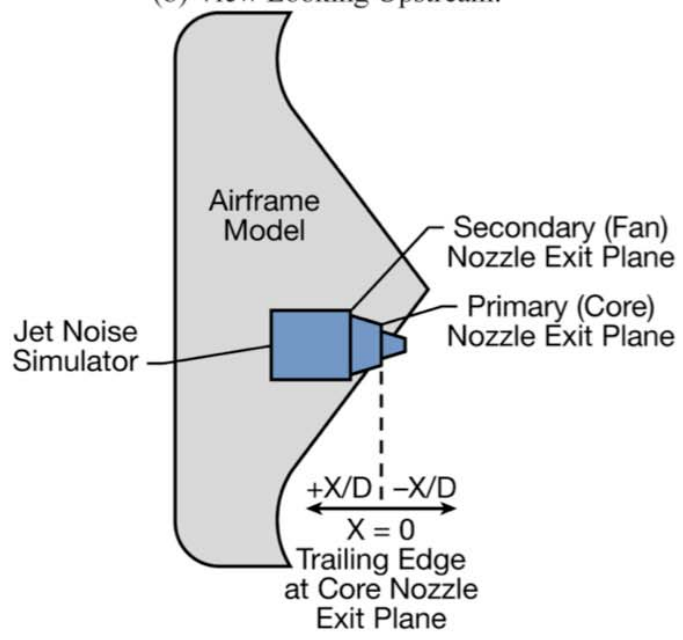

(c) Side View with $X$, Axial Coordinate Definition.

Figure 4 a, b, and c. Schematic of the LSAF wind tunnel set-up (not to scale). a. Top view of the LSAF test section, b. View looking upstream, and c. Top view showing $X$ coordinate definition (+X/D for the jet core nozzle exit plane upstream of the trailing edge). (Figure from Reference 12) 
In the study of Reference 12 , there is a discussion of the challenge of positioning the jet engine simulator and nozzle in proximity to a planform like the HWB with its large area. The approach used in Reference 12 was to construct a special nozzle extension (seen in Figure 3 of Reference 12). In Figure 5 of Reference 12, the effect of this extension on the quality of jet noise from the standard jet engine simulator configuration is shown to be minimal. This nozzle extension allowed the nozzle to be placed within the design guidance for vertical spacing for an HWB application. Figure 25 of Reference 12 also shows that the vertical spacing parameter has a relatively weak effect on total installed jet noise reduction over a wide range of the Y/D parameter (at the baseline $\mathrm{X} / \mathrm{D}$ station). In the current study at a bypass ratio of 10 with a lower overall jet noise level there results a greater requirement for avoiding background noise contamination. Given the results of Reference 12 just cited and to balance technical risk and relative importance of the Y/D parameter, it was decided for this study to use the standard jet engine simulator configuration without the nozzle extension in order to have the highest quality jet noise source. The consequence was that the nozzle centerline could be positioned only as

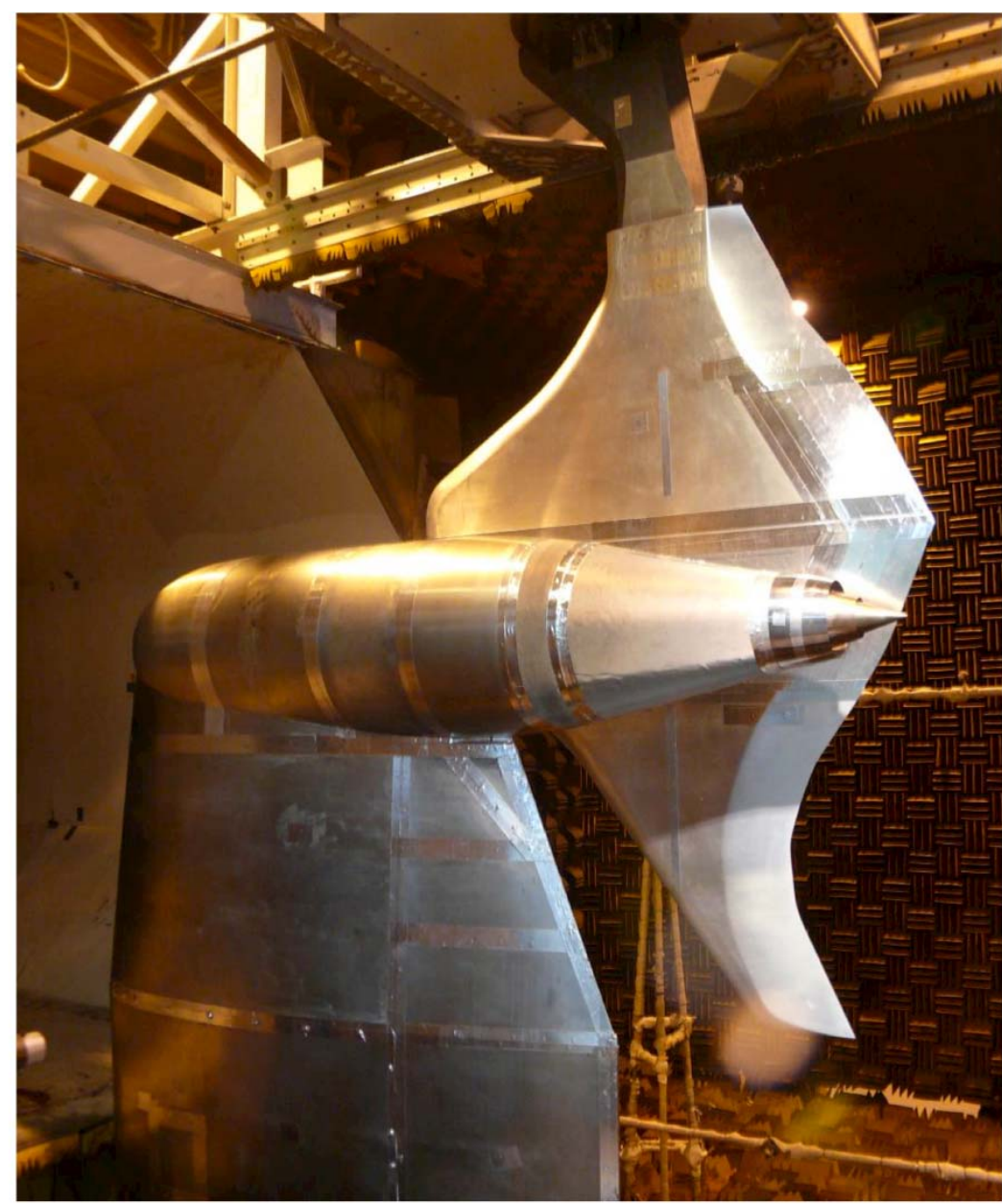

Figure 5. Close up photograph of the LSAF experimental set-up with the jet engine simulator and clean airframe planform model. close as $\mathrm{Y} / \mathrm{D}=1.73$; however, again referring to the cited results in Reference 12, the difference should be minimal between the installed jet noise at this vertical spacing and that from the HWB nominal spacing of $\mathrm{Y} / \mathrm{D}=0.88$.

To focus on the most important parameters for acoustics at the best value, the HWB planform airframe designed was a simplified model. While not having a full 3D aerodynamic moldline, the airframe model does have the highest priority features for an acoustic study including a representative planform shape, realistic NACA airfoil section leading and trailing edges, HWB vertical surfaces that can be varied in size and cant angle and elevons that can be varied in deflection angle. While the key parameters for installed jet noise can be investigated with this model, one disadvantage is that the model cannot be taken to angle of attack with tunnel flow on.

The Boeing LSAF jet engine simulator was supported from below the open jet and is fixed in position. The LSAF jet rig produced flow conditions matching realistic, hot jet conditions for the N2A bypass ratio 10 cycle and, together with high fidelity nozzle and pylon geometries, resulted in a high-quality simulation of full-scale jet source noise. In addition, the LSAF jet rig used a boundary layer suction system upstream of the fan nozzle that can be seen in Figure 5. The boundary layer suction system removes the boundary layer on the external surface of the jet rig so that the boundary layer thickness approaching the fan nozzle chevron more closely represents application at full scale. Tests were also performed to insure that the noise from the suction system itself were well below the jet noise levels.

The spectral data presented in this paper are model scale data extrapolated to full scale at a nominal HWB flight path. With the scale factor of $6.2 \%$ the $80 \mathrm{kHz}$ model scale one-third octave band translates to $4.9 \mathrm{kHz}$ full scale. The extrapolation process artificially rolls off the spectra for higher frequencies. The atmospheric attenuation coefficients were obtained from the method of Shields and Bass ${ }^{16}$. 
Phased microphone arrays were used to localize and quantify the levels of acoustic sources using 416 Brüel \& Kjær 1/4-inch type 4938-W-001 microphones (with B\&K 2670-W-001 preamplifiers). The microphones were flush mounted in a flat plate positioned 131.6 inches laterally from (and parallel to) the streamwise oriented vertical analysis plane passing through the far-field (polar) microphone array origin. The plate was attached to a mobile cart allowing for a wide range of phased array polar angle positions spanning from 50 to 150 degrees. Phased array measurements were acquired largely at geometric angles of 50,90,120, and 150 degrees with measurements at intermediate angles of $60,70,80,100,110,130$, and 140 degrees also acquired for certain cases. At the polar angle of 90 degrees, the phased array origin was centered on the primary nozzle exit plane. When acquiring far-field acoustic data, the cart was traversed to a stowing location behind the tunnel contraction.

The phased array consisted of four subarrays of various sizes, where the subarrays provided overlapping coverage over the frequency ranges of interest. The four subarray sizes are referred to as: small (S), medium (M), large (L) and extra large (XL), with the baseline subarrays containing, respectively, 170, 199, 110 and 170 microphones. The horizontal/vertical subarray apertures were approximately 12 in. x 9 in (S), 26 in. x 20 in. (M), 58 in. $x 44$ in. (L) and 126 in. $x 96$ in. (XL) in size. A sharing of microphones between the various subarrays was used to reduce the overall microphone count.

Conventional beamforming was used for all of the phased array processing. In order to enhance the spatial resolution in the beamform maps, the diagonal of the cross-spectral matrix was replaced by the row average. A ray tracing algorithm based on Pierce ${ }^{17}$ was used to account for the presence of the wind tunnel shear layer. In the implementation algorithm, the shear layer half-velocity distribution at any given $\mathrm{X}$ location cross-section was modeled as an ellipse. The model worked fairly well over a wide range of phased array geometric measurement angles. At the extreme angles (approximately 50 degrees and larger than 130 degrees), shifts in the measured source locations from the expected locations arose, and are attributed to increased differences between the modeled and actual (unknown) shear layer location and shape. A qualitative shifting of the beamform map images allows for a better matching between the measured and expected source locations at these extreme angles. The beamforming grid was a rectangular with 0.25 inch separation between grid points in both the $\mathrm{X}$ and $\mathrm{Z}$ dimensions. The grid was fixed in position and centered at the Y-axis location of the jet nozzle centerline.

Table 1. Nozzle fan, core, plug, and pylon components used in assembling nozzle configurations.

\begin{tabular}{|c|l|}
\hline Fan Nozzles & Description \\
\hline F1 & Baseline, conventional round (no chevron, no pylon) \\
\hline F2 & Uniform chevrons with no pylon \\
\hline F3 & T-fan (circumferentially non-uniform) with pylon, immersion similar to best from Ref. 12 \\
\hline F4 & T-fan with pylon, circumferentially consistent increased chevron immersion relative to F3 \\
\hline F5 & Same as F8 except for increased immersion for four consecutive chevrons, no pylon \\
\hline F8 & T-fan chevron type with no pylon, chevron parameters consistent with F3 \\
\hline F9 & Baseline, round with pylon (no chevrons) \\
\hline Core Nozzles & \\
\hline C1 & Baseline, conventional round (no chevrons) \\
\hline C2 & Chevrons \\
\hline Plug & \\
\hline P1 & Baseline, conventional plug for BPR 10 \\
\hline Pylon & \\
\hline & Conventional pylon type for large twin aisle aircraft application \\
\hline
\end{tabular}

\section{Configurations}

The results and lessons from the prior work ${ }^{12}$ were factored into the current study for application to the higher bypass ratio 10 nozzles. The results shown in this paper were produced from a total of seven fan nozzles, two core nozzles, one plug, and one pylon designed for this study. These nozzles and pylon could be combined in several nozzle configurations to accomplish the objectives of this study. The nozzle components are listed in Table 1 . All of these nozzles are sized for the BPR 10 cycle of Table 2 and for the thrust requirement, at this model scale, of the application to the Efficient Low Noise HWB of Ref. 15. Because the nozzle configurations include those with and 
Table 2. Nozzle gas conditions as function of Thrust Fraction (\% of full thrust).

\begin{tabular}{|c|c|c|c|c|c|}
\hline $\begin{array}{c}\text { Thrust } \\
\text { Fraction, \% }\end{array}$ & TTR $_{\mathbf{p}}$ & $\mathbf{N P R}_{\mathbf{p}}$ & $\mathbf{T T R}_{\mathbf{s}}$ & $\mathbf{N P R}_{\mathbf{s}}$ & $\begin{array}{c}\text { Test Condition } \\
\text { Code }\end{array}$ \\
\hline $\mathbf{1 0 0 ,}$ Sideline & 2.956 & 1.412 & 1.161 & 1.611 & 2121 \\
\hline $\mathbf{9 0}$ & 2.874 & 1.339 & 1.147 & 1.560 & 2929 \\
\hline $\mathbf{8 0}$, Cutback & 2.784 & 1.280 & 1.134 & 1.506 & 2828 \\
\hline $\mathbf{7 0}$ & 2.700 & 1.228 & 1.122 & 1.451 & 2727 \\
\hline $\mathbf{6 0}$ & 2.620 & 1.183 & 1.109 & 1.396 & 2626 \\
\hline $\mathbf{5 0}$ & 2.533 & 1.142 & 1.096 & 1.341 & 2525 \\
\hline $\mathbf{4 0}$ & 2.431 & 1.106 & 1.082 & 1.285 & 2424 \\
\hline
\end{tabular}

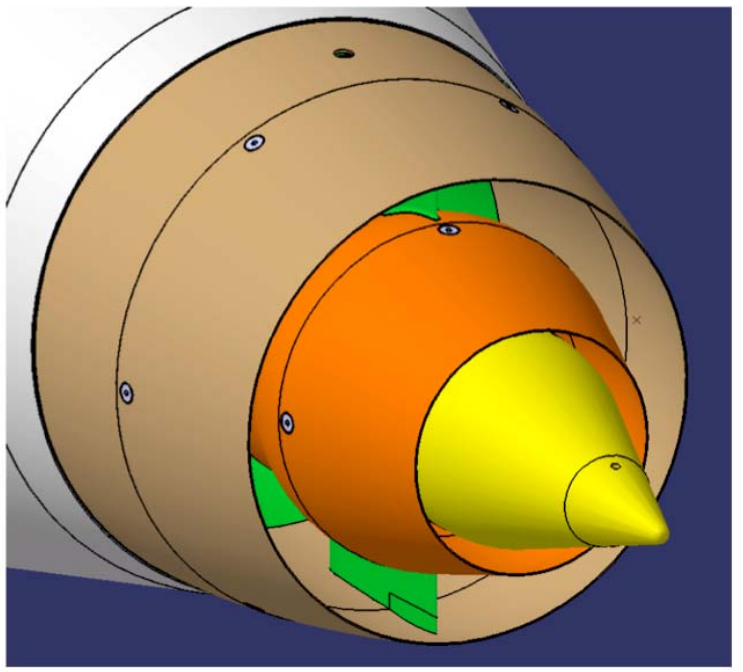

Figure 6. F1+C1 nozzle configuration.

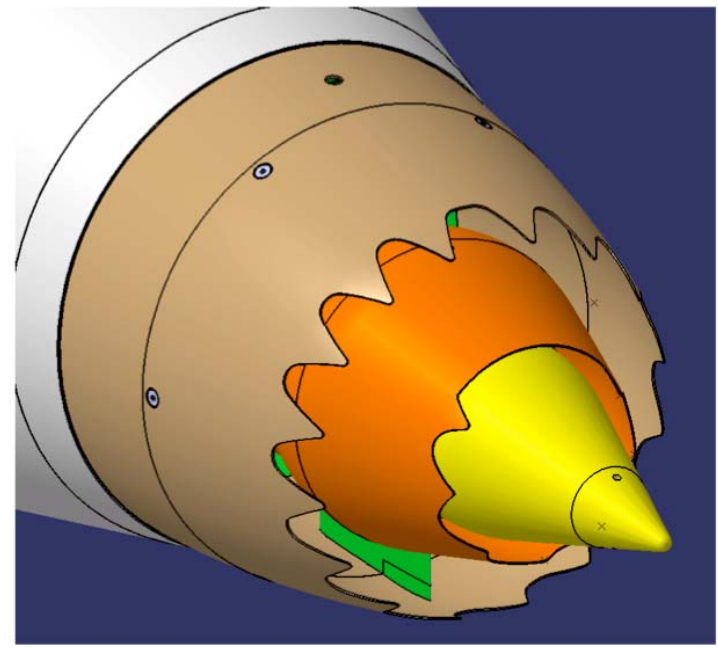

Figure 7. F2+C2 nozzle configuration.

without chevrons and a pylon, the design process was performed with the requirement of equivalent thrust from the different configurations.

Fan nozzle F1 combined with core nozzle $\mathrm{C} 1$ and plug P1 represents the baseline, conventional round BPR 10 nozzle with no pylon and no chevrons and this combination is shown in Figure 6. All configurations in this paper use plug P1. The prior study ${ }^{12}$ had only used the T-fan chevrons ${ }^{9}$, designed with a conventional pylon. This chevron type had been shown to be the best chevron design for community noise reduction for both conventional isolated and HWB shielding applications. Therefore, the current study also sought to determine, for this over-the-wing HWB configuration, the impact of a conventional chevron that is circumferentially uniform, F2, relative to the T-fan type chevrons, both with and without a pylon. This approach would allow new insight into the effects of chevron type and of the pylon compared to the prior study. The combination of F2 with the core chevron nozzle, $\mathrm{C} 2$, is shown in Figure 7. The core chevron nozzle, $\mathrm{C} 2$, can be seen to have a gap in the otherwise uniform circumferential chevrons. This gap allows $\mathrm{C} 2$ to also be used with a pylon.

Fan nozzle F3 includes T-fan chevrons with a pylon, shown in Figure 8 with core chevron C2 and the conventional pylon, S1. This configuration, now applied to the BPR 10 cycle, is the same design type of the best nozzle configuration selected in the prior work ${ }^{12-13}$ for the BPR 7 application. The T-fan chevrons are designed similarly to the chevron termed Chev2 of Czech, Thomas, and Elkoby ${ }^{12}$. The pylon, S1, is also similar in design to the pylon used in the prior study ${ }^{12}$ with it strong acoustic effect, now translated to the BPR 10 specifications.

Fan nozzle F4 represents another T-fan chevron that extends the same design guideline by increasing immersion of the chevron into the flow further compared to F3. Thus, F4 represents an effort to further map out the design space for this application to determine if additional installed jet noise reduction can be obtained.

Another new design compared to those in Ref. 12 is fan nozzle F8 where a T-fan type chevron is designed without a pylon. This design allows the best separation of the effects from the asymmetry of the T-fan and the pylon. Figure 9 shows F8 with core nozzle C2. The gap in the chevrons on core nozzle C2 was noted above. On this fan nozzle a smaller gap can also be seen in fan chevrons (at the top center of F8). This small gap is a result of applying 


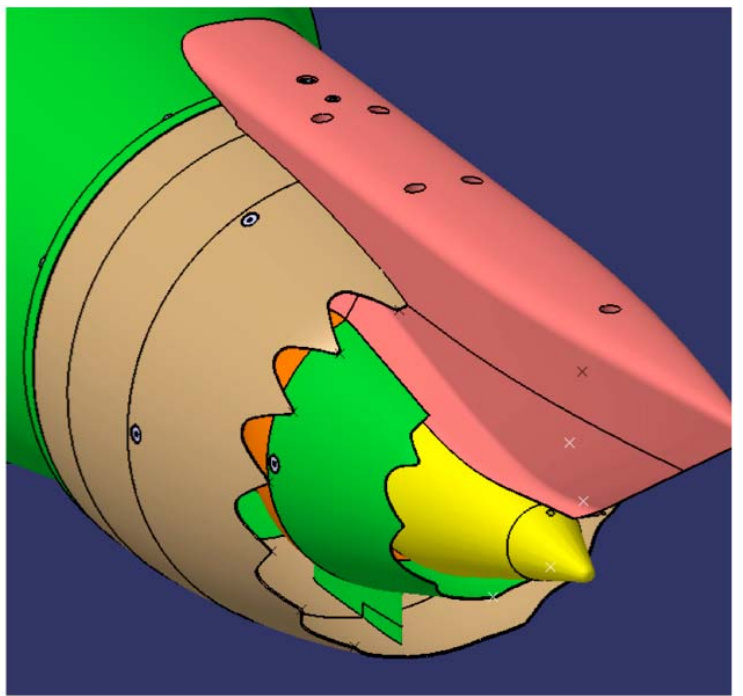

Figure 8. F3+C2+S1 nozzle configuration.

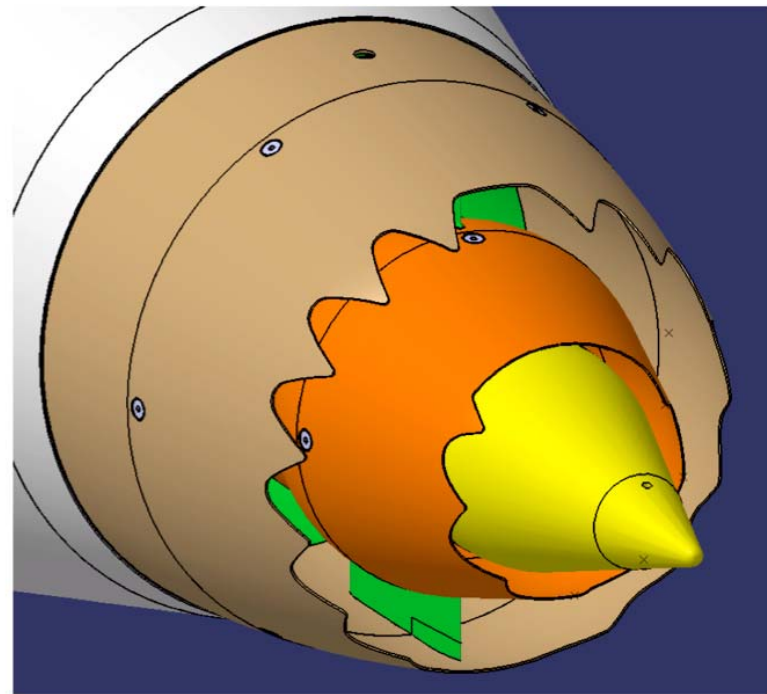

Figure 9. F8+C2 nozzle configuration.

the same T-fan chevron design from F3, with a pylon, to F8 without a pylon. The area of the pylon requires an adjustment in the area of the fan nozzle and therefore changes the circumference of the fan nozzle resulting in adjustments to the chevron design parameters.

Fan nozzle F5 is similar to F8 except that there is additional immersion of only the four consecutive chevrons in the vicinity of where the pylon would be. The idea was to attempt to use the increased immersion of these top four chevrons to favorably increase the asymmetry of the basic T-fan design similar to the additional asymmetry of the pylon. This design, however, did not show any significant improvement and is noted here only as an indication of how the design space was explored.

\section{Results}

The nozzle configurations from Table 1 were tested first isolated, without the airframe, in order to document their isolated noise characteristics. Based on these results, a smaller test matrix was then prioritized for the installed portion of the experiment.

\section{A. Isolated Nozzle Results Without Pylon}

The first comparison of isolated jet noise contrasts the characteristics of the uniform chevrons, fan nozzle F2, with the T-fan type chevron, F8, both without a pylon. Figure 10 shows the F2 and the F8 chevron nozzles compared to the baseline nozzle, F1. Figure 10 uses a standard format that will be used in several figures and includes two types of data presentations. First, there is a one-third octave spectra comparison of configurations at six polar angles from upstream, 55 degrees, to downstream, 145 degrees (relative to the inlet axis). Second, are two difference plots, or delta contour plots, to more easily highlight differences between the spectra shown as a function of frequency and emission angle. The difference contour plots use data from all 16 polar array microphones. The data plotted in Figure 10 are from the polar array at azimuth angle of 90 degrees, adjusted to full scale, and are for the conditions of a wind tunnel Mach number of 0.24 and the sideline gas condition, equal to $100 \%$ thrust fraction. The apparent "knee" that can be seen sometimes in the spectra at about $5 \mathrm{kHz}$ is due to the artificial roll-off in the full scale extrapolation where no model scale data exist at frequencies above the knee. The left contour plot of Figure 10 shows the difference of F2 (set-up two in the spectral plot order) and F1 (set-up one in the spectral plot order). Both the spectral plots and the left contour plot show that the nozzle with F2 reduces the low frequency over the entire polar angle range but also has a noise increase at the higher frequencies over the entire range of polar angles. The cross-over frequency is at about 500 to $600 \mathrm{~Hz}$ corresponding to the $27^{\text {th }}$ to $28^{\text {th }}$ band number (Band number $=$ $10 * \log (f)$ ). While the contour plots have a range fixed at $\pm 3 \mathrm{~dB}$, the spectral plots can be used to see that the low frequency reduction is as much as $4 \mathrm{~dB}$. The left contour plot shows the high frequency increase in better detail, 

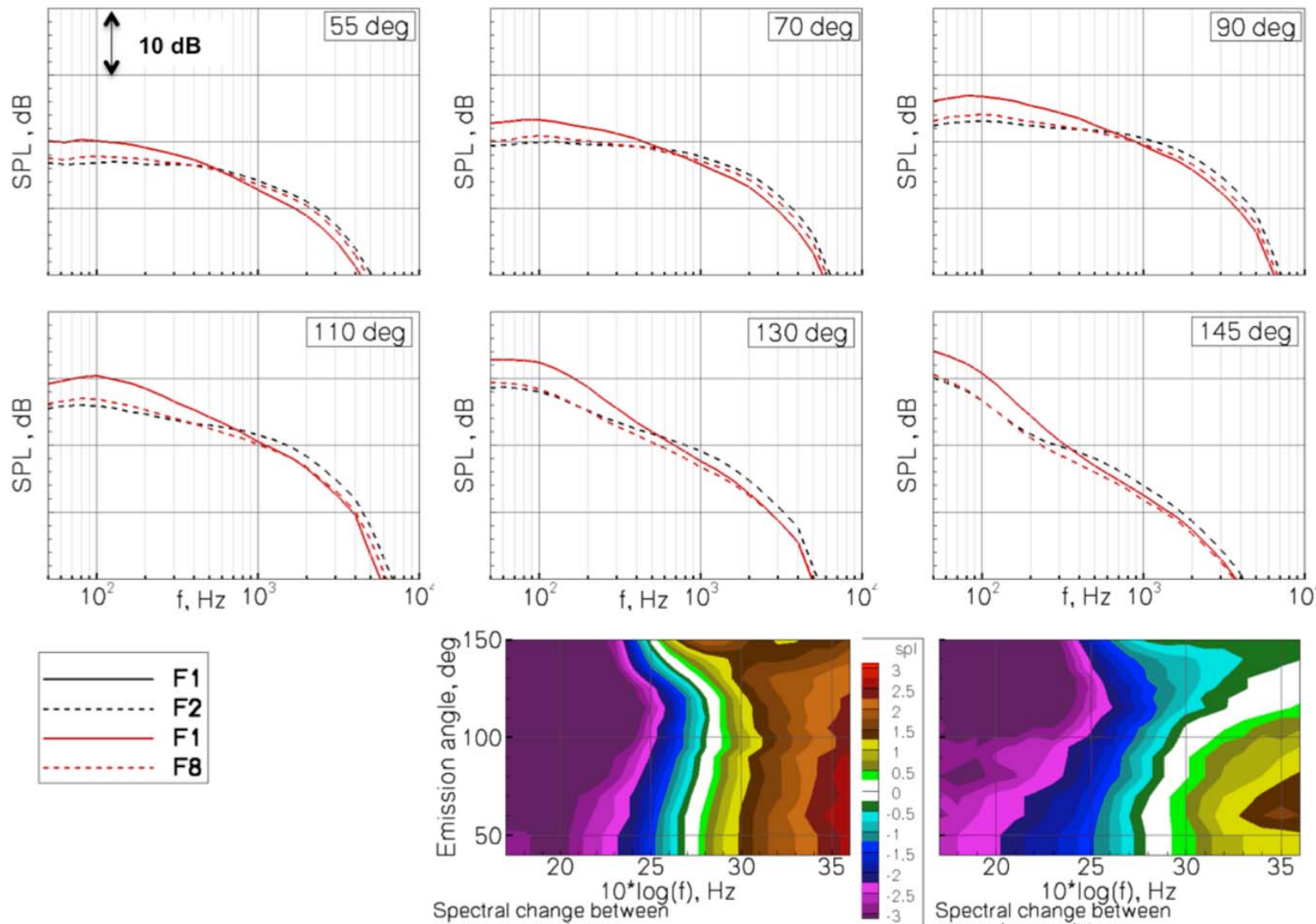

set-uo two and one

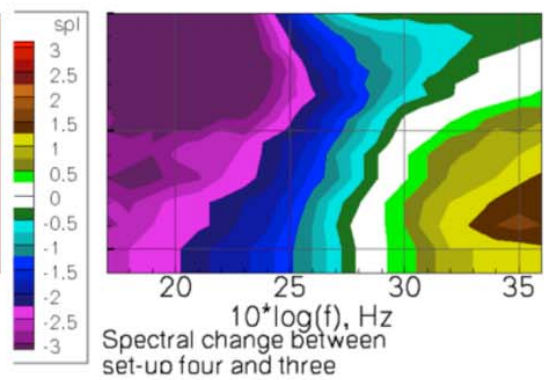

Figure 10. Spectral line and contour comparison of the nozzle configurations with the baseline fan nozzle F1 (baseline core nozzle C1), uniform fan chevron nozzle F2 (core chevron nozzle C2), and the T-fan type fan chevron nozzle F8 (core chevron nozzle $\mathrm{C2}$ ). Full scale, sideline gas condition, and $M_{\mathrm{T}}=0.24$. Note: F1 is plotted twice in the line plots, the solid red line shows over the solid black line.

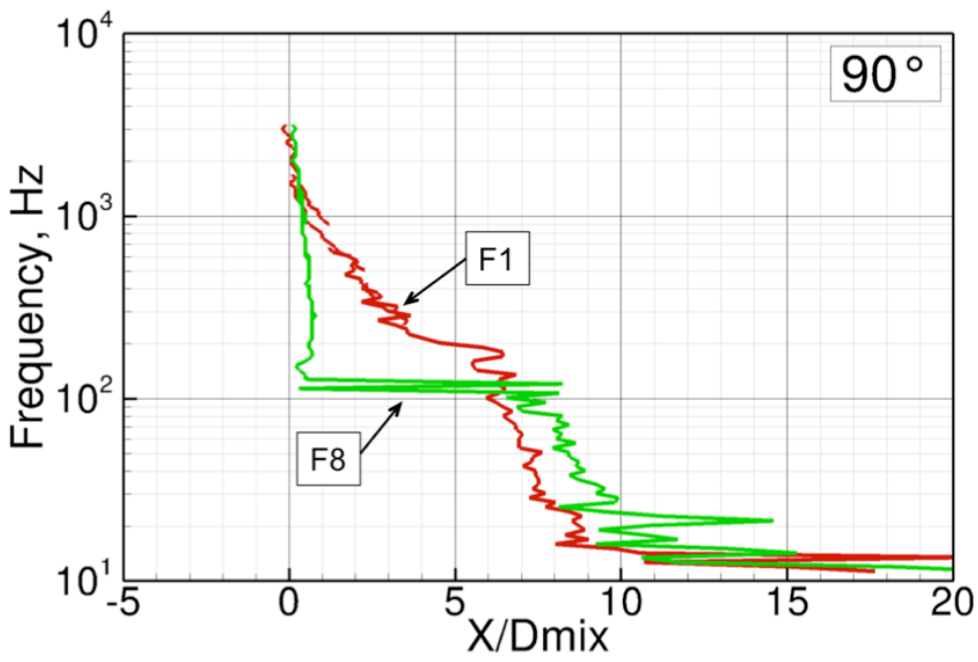

Figure 11. Axial peak noise source location non-dimensionalized by mixed jet diameter as a function of frequency for the baseline F1 nozzle and the $\mathrm{T}$-fan chevron $\mathrm{F} 8$ nozzle. Results from phased array shown at the 90 degree polar angle only. Full scale, sideline gas condition, and $\mathrm{M}_{\mathrm{T}}=\mathbf{0 . 2 4}$. from 1 to $2 \mathrm{~dB}$ increase over all angles and even some increases of up to $2.5 \mathrm{~dB}$ in the forward angles at the highest frequencies.

Figure 10 also shows the results for the T-fan chevron nozzle F8. Compared to the uniform chevron, F2, F8 achieves slightly less reduction for low frequencies from the baseline nozzle F1, except at the highest, downstream, polar angles. The comparison for higher frequencies is more significant when anticipating how these two nozzles will perform installed. The F2 uniform chevron has more of an increase over a wider range of polar angles compared to the F8 T-fan nozzle. In fact, at the most downstream angles the F8 nozzle even has a small decrease in noise relative to the baseline $\mathrm{F} 1$ of $0.5 \mathrm{~dB}$ 
while the F2 nozzle has an increase of up to $1.5 \mathrm{~dB}$.

Given that jet noise at downstream angles is the most challenging to shield and that the F8 T-fan nozzle shows only a very small increase at low frequencies compared to the F2 nozzle and even some decreased noise at high frequencies compared to F1, these isolated results indicate that the F8 nozzle will have the more favorable installed noise performance.

Phased array data were used to locate the peak noise source as a function of frequency. Figure 11 shows the results for the F8 nozzle compared to the baseline F1 nozzle. Several observations can be made, particularly in the context of the BPR 7 results of Reference 12, Figure 16. First, for the baseline nozzle, F1, peak high frequency sources are closer to the nozzle exit and low frequency sources are 5 to 10 diameters downstream. Also, there is a frequency, in this case at $3000 \mathrm{~Hz}$ or close to band 35, where the peak source abruptly shifts from downstream, more than 5 diameters, to more upstream or less than 5 diameters. However, compared to the BPR 7 results the BPR 10 "shift" upstream is less abrupt and now occurs at a much lower frequency of about $200 \mathrm{~Hz}$ or band 23.

For the chevron nozzle in Figure 11, F8 in this case, the effect on peak source location is very similar to that seen in the BPR 7 results of Reference 12. The chevron moves peak high frequency sources closer to the nozzle exit however, for frequencies lower than the shift frequency the peak sources are actually moved farther downstream. It can also be observed that the F8 chevron's shift frequency is at $100 \mathrm{~Hz}$ or close to band 20, and this is a lower frequency than the band 24 frequency, $250 \mathrm{~Hz}$, of the best chevron, Chev2, of Reference 12 at BPR 7. This is an
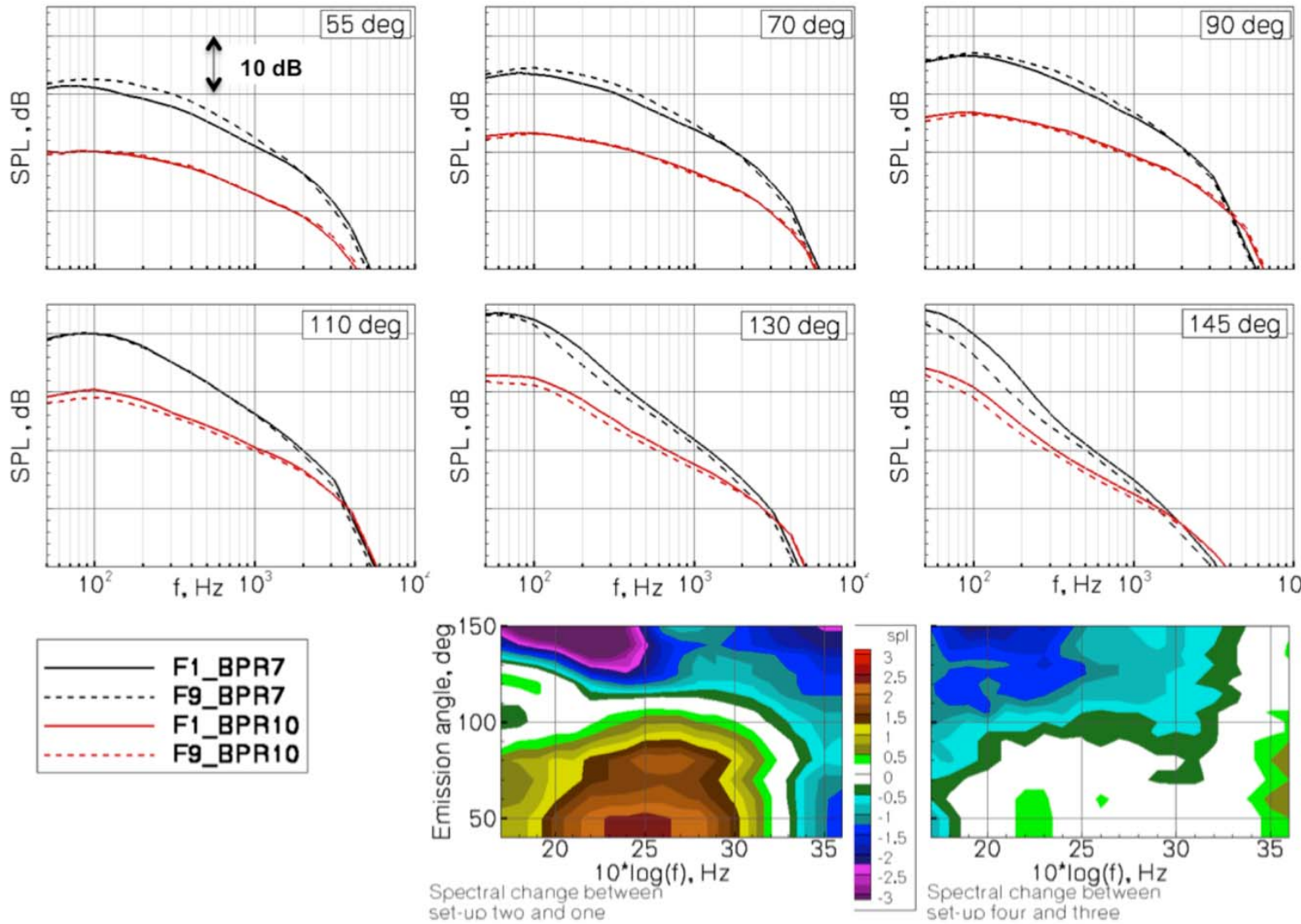

Figure 12. Spectral line and contour comparison of the pylon effect at both BPR 7 and BPR 10. Full scale, sideline gas condition, and $\mathrm{M}_{\mathrm{T}}=\mathbf{0 . 2 4}$.

important indication of the effect of bypass ratio, while chevrons are still effective at moving peak sources upstream, the higher bypass ratio already has had much effect of upstream shifting of peak sources.

\section{B. Isolated Nozzle Results With The Pylon}

Czech, Thomas, and Elkoby ${ }^{12}$ documented the effect of the pylon on isolated jet noise for BPR 7. At this BPR the effect of the pylon creates several changes in the level and directivity that are beneficial for the shielding 
application. As a result, the best nozzle configuration included a standard pylon oriented at 270 degrees or the "crown" position relative to the airframe and observers (see Figure 4). The standard pylon was shown to have a strong acoustic effect on polar and azimuthal directivity that combined positively as part of the best nozzle configuration.

The new results in this paper extend the understanding of the pylon effect as shown in Figure 12. For both BPR 7 and 10 the baseline nozzles, F1, and the nozzles with the same pylon type, F9, are designed with equivalent areas and thrust. The left contour plot shows the difference with a pylon at BPR 7 and, as described in Reference 12, the effect of the pylon at this BPR is significant, resulting in increased noise levels in the forward angles and decreased levels in the most downstream angles.

The effect of the pylon at BPR 10 is shown in the right contour plot of Figure 12. The effect is significantly reduced compared to that at BPR 7, smaller reductions in noise levels at the downstream angles and the absence of the increased levels in the forward angles. Clearly, for BPR 7 and below the pylon effect is strong, however, by BPR 10 the effect is reduced and is consistent with the trend of reduced mixed jet velocities as BPR increases. However, even though the pylon effect is reduced at BPR 10, it is still potentially beneficial for shielding applications because of the reduced levels in the far downstream angles, the most difficult angles to obtain reductions from shielding.

Figure 13 demonstrates the result of the addition of the T-fan chevron with the pylon, the F3 fan nozzle with the $\mathrm{C} 2$ core chevron nozzle and the S1 pylon, compared with the T-fan chevron, F8, without a pylon. Looking at the downstream angles of 130 and 145, the F3 nozzle and pylon combination do show reduced levels of noise at low frequencies compared to the F8 nozzle. This may be indicative of the small but still beneficial pylon effect at BPR 10. However, the high frequency increase is overall lower for F8 as compared to F3. Installed, shielded measurements will determine which produces overall lower noise levels for this particular application and will be shown in the next section.
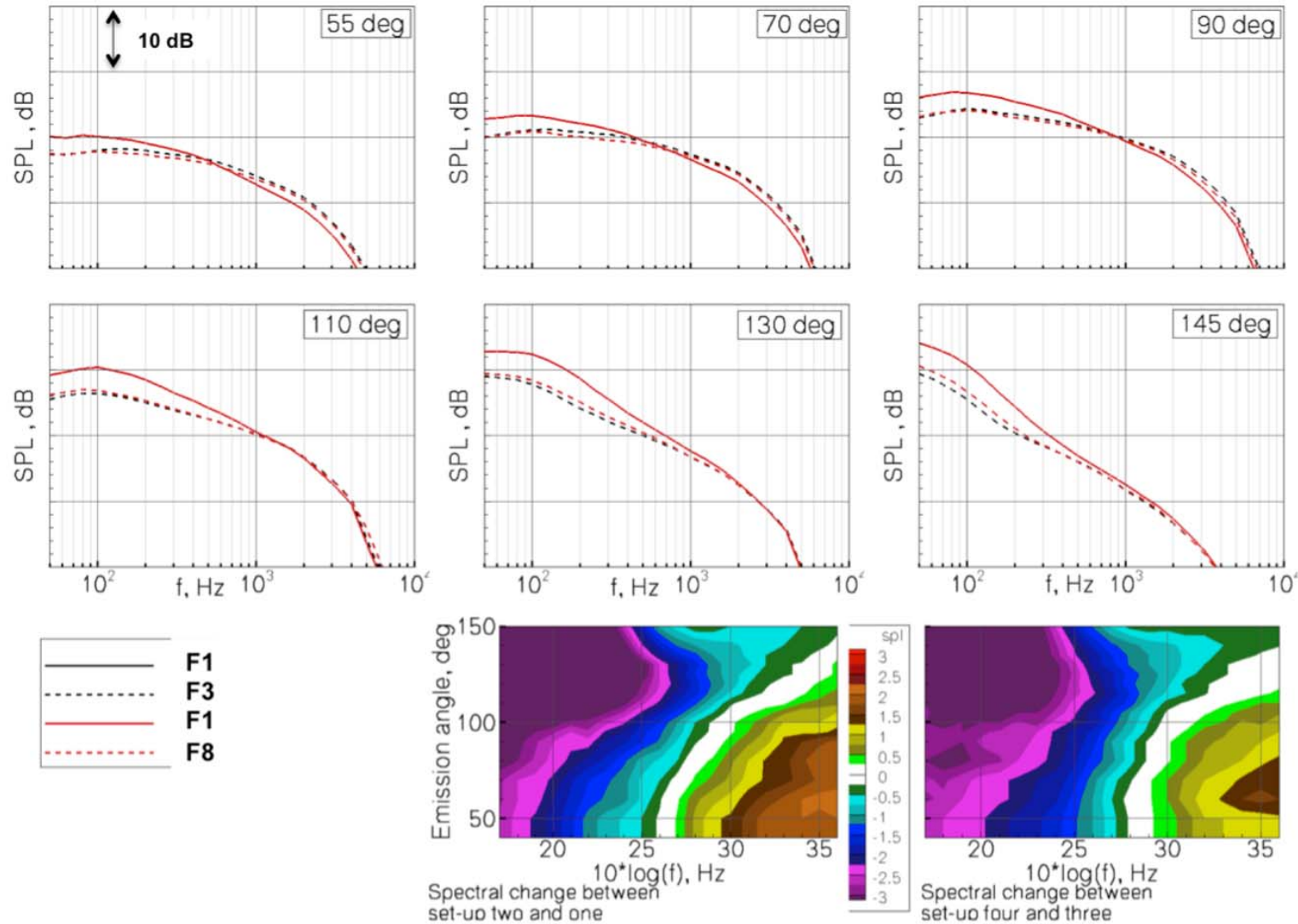

Figure 13. Spectral and contour comparison of $T$-fan chevron without a pylon, F8, T-fan chevron with a pylon, F3, and the baseline, F1, without chevrons and without pylon. Full scale, sideline gas condition, and $\mathrm{M}_{\mathrm{T}}=\mathbf{0 . 2 4}$. 
Designing the chevrons to be more immersed into the fan flow, or more aggressive, than otherwise practical for an unshielded application was found to be of overall benefit in Reference 12 because the additional low frequency reduction was contributory while the increased high frequency increase could be somewhat shielded. This approach was also extended in the present work by immersing the chevrons of nozzle F4 more as compared to those of F3. The isolated test result comparing the two is shown in Figure 14. It appears that the limit of this design parameter

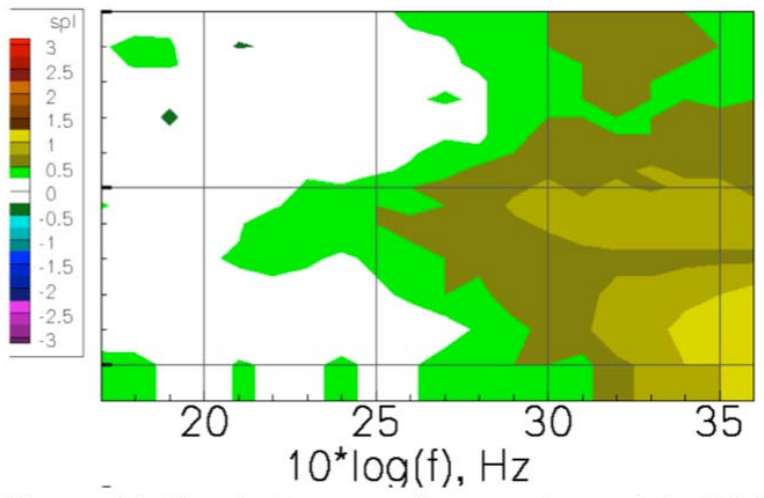

Figure 14. Spectral comparison contour plot of $F 4$ relative to $\mathbf{F 3}$. Full scale, sideline gas condition, and $\mathrm{M}_{\mathrm{T}}=\mathbf{0 . 2 4}$.
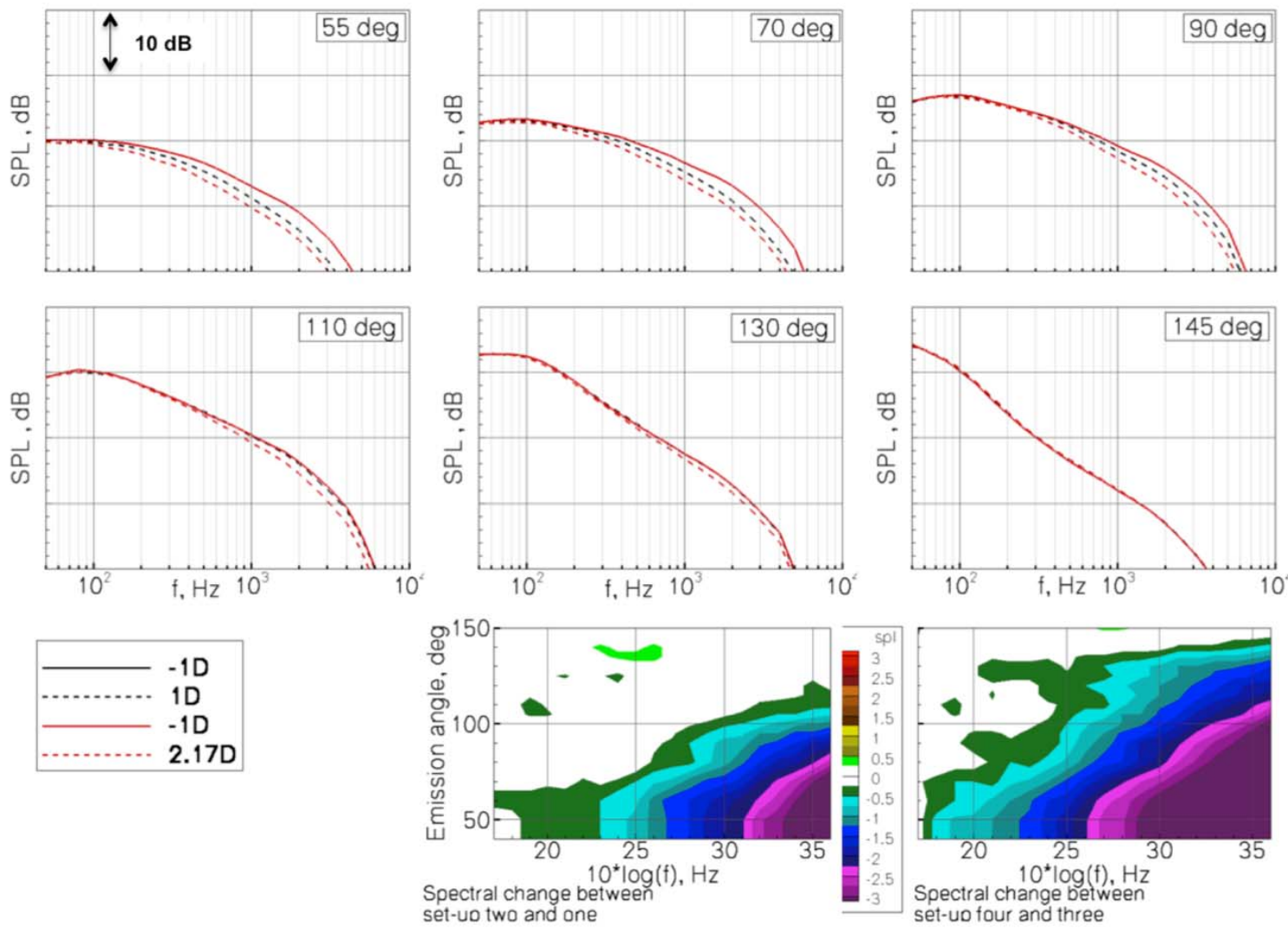

Figure 15. Influence of axial position of the nozzle relative to the airframe for $F 1$ fan nozzle, unshielded -1D, shielded by 1D upstream of trailing edge, and at 2.17D upstream of the trailing edge. Full scale, sideline gas condition, and $\mathrm{M}_{\mathrm{T}}=\mathbf{0 . 2 4}$. 
airframe is not present or true isolated jet noise. As the jet is moved to the position of $\mathrm{X}=1 \mathrm{D}$ upstream of the trailing edge there is some noise reduction due to shielding that increases with forward angle and some noise reduction that increases with frequency corresponding to the fact that higher frequency sources are closer to the nozzle exit. At most downstream polar angles there is very little to no reduction from shielding. For the position of $\mathrm{X}=2.17 \mathrm{D}$ there is more shielding evident; however, in the downstream polar angles there is still very little reduction even at the high frequencies and no reduction for low frequencies. This illustrates again, even at this bypass ratio, how important the chevrons are to achieving a total installed jet noise reduction.

Figure 16 demonstrates the noise reduction from shielding by this airframe that is achievable for the T-fan type chevron nozzle, F8, without a pylon, as a function of axial distance relative to the trailing edge. Again, Figure 16 shows the shielded results compared to the same nozzle effectively isolated. Compared to the baseline nozzle shown in Figure 15, the F8 nozzle produces much larger reductions in the upstream angles, up to $8 \mathrm{~dB}$ for angles less than 90 degrees. Also there is some more noise reduction at the downstream angles, up to 130 degrees. In general, a much stronger trend of noise reduction with aft shield area, clearly correlating with the phased array results showing
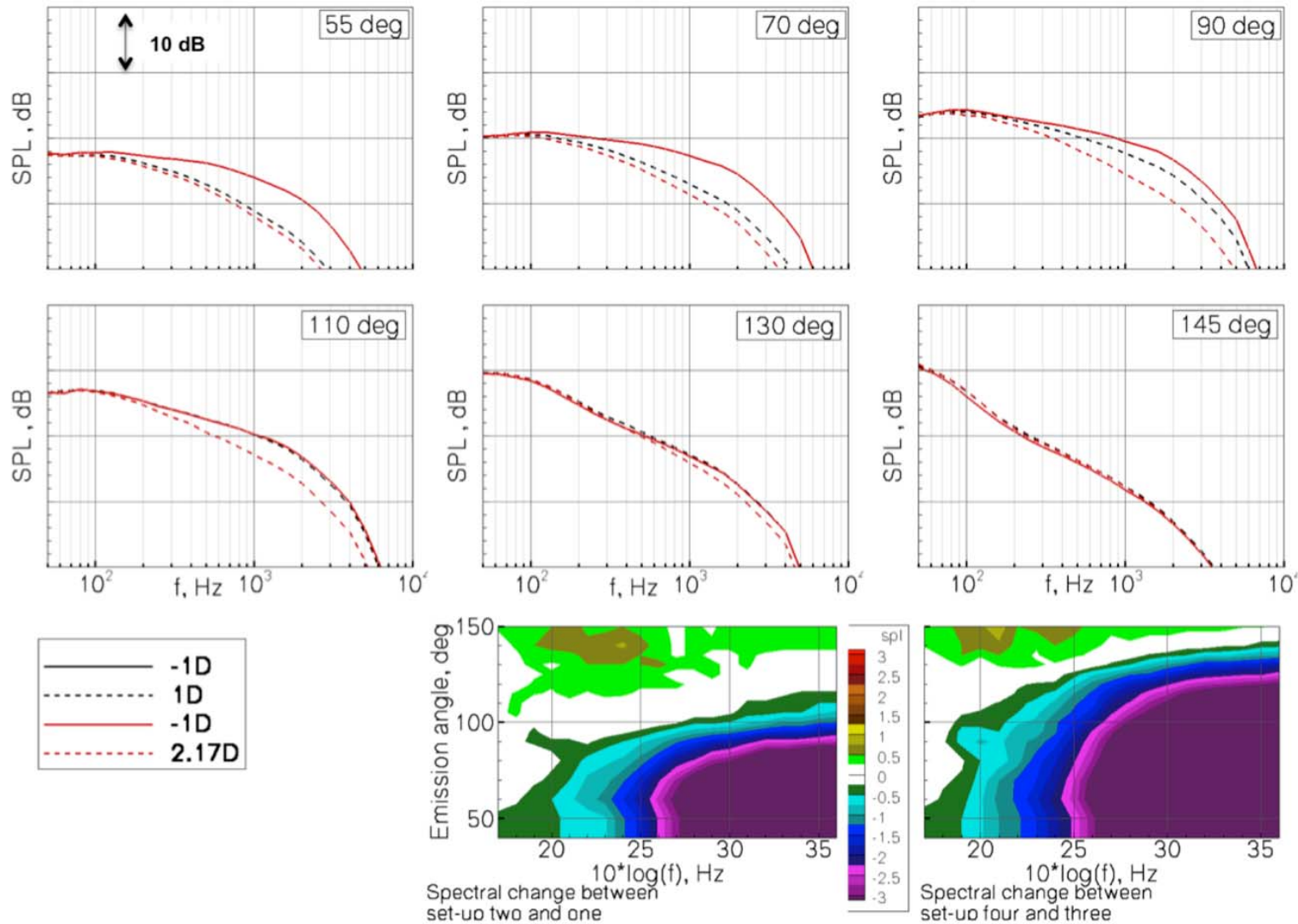

Figure 16. Influence of axial position of the nozzle relative to the airframe for $F 8$ fan nozzle, unshielded $-1 \mathrm{D}$, shielded by 1D upstream of trailing edge, and at 2.17D upstream of the trailing edge. Full scale, sideline gas condition, and $\mathrm{M}_{\mathrm{T}}=\mathbf{0 . 2 4}$.

more upstream location of peak noise sources over a larger frequency range compared to that of the baseline nozzle.

Now a direct comparison of F8 and F1 at the nominal design location of $\mathrm{X} / \mathrm{D}=2.17$ is shown in Figure 17. The benefit of the chevrons for low frequency, downstream angle reduction is evident with more than $3 \mathrm{~dB}$ lower levels for the F8 nozzle. Upstream the F8 also has lower levels by 1 to $3 \mathrm{~dB}$ over the frequency range. Only at the highest downstream angles and highest frequencies is there little difference between the two nozzles.

To this point, it has been shown that for this application the T-fan chevron is superior to the uniform chevron (Figure 10) and that the pylon effect is still potentially beneficial (Figure 12). Furthermore, isolated results (Figure 13) showed that the T-fan with pylon (F3) was similar to the F8 nozzle (without pylon). This leads to the comparison between F3 and F8 at the design location of 2.17D shown in Figure 18. As in the isolated comparison, there is still not a clear differentiator between the two although the F3 nozzle does have slightly lower levels in the 

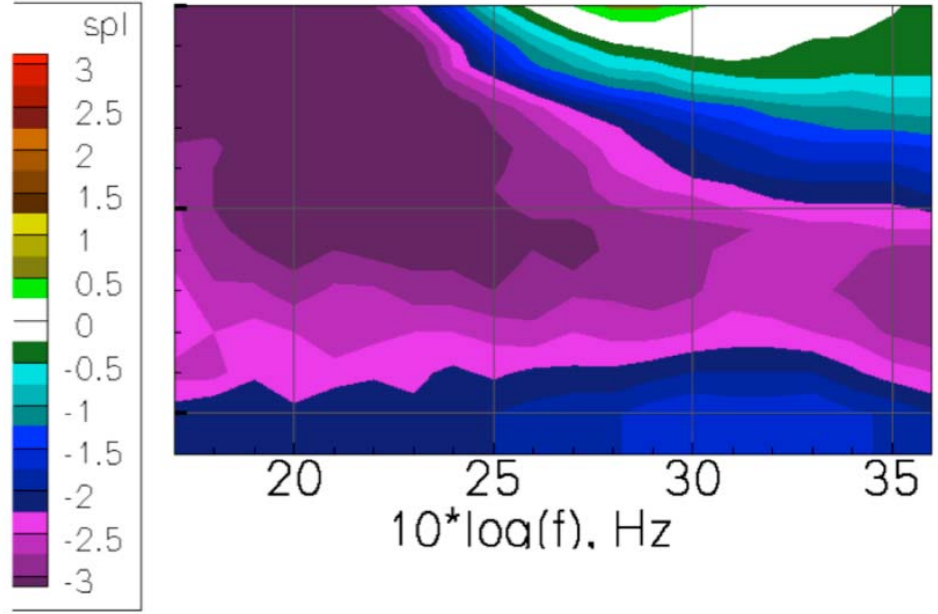

150

ర্త

100

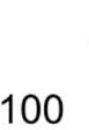

Figure 17. Comparison of F1 and F8 at the installed location of 2.17D upstream of trailing edge. F1 is subtracted from F8. Full scale, sideline gas condition. and $M_{T}=0.24$.

weight and cost of the pylon, particularly this one in the crown position that is separate from the keel pylon attaching the nacelle to the HWB (see Reference 12), clearly F8 represents the simpler and better overall choice.
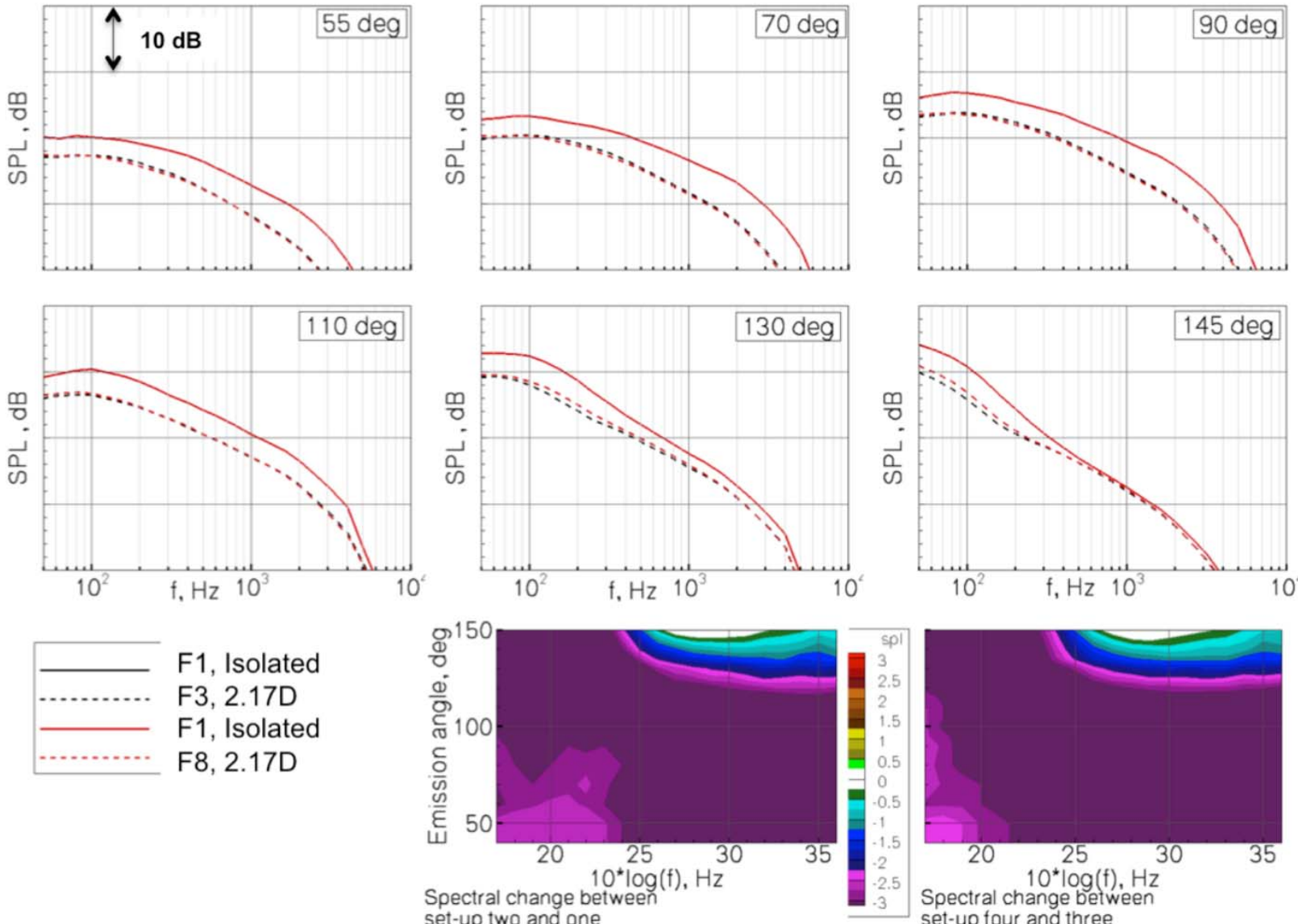

Figure 18. Spectral comparison of F3 and F8, both at 2.17D upstream of trailing edge, with the baseline nozzle $F 1$ isolated. Full scale, sideline gas condition, and $M_{T}=0.24$. 


\section{Additional Airframe Effects}

With the F8 nozzle (and C2 core nozzle) selected as the best overall nozzle based on installed testing in a clean airframe configuration (clean airframe shown in Figure 5), further measurements were performed to include additional airframe installation effects. These additional effects included those from the vertical surfaces, cant angle of the vertical surfaces, and elevon deflection angle. Two sizes of vertical surfaces were available however, based on prior studies ${ }^{12}$ the effect of different size verticals is small, thus only the baseline vertical was used. This was tested at two cant angles of 102 and 120 degrees (where 90 degrees would be normal to the airframe surface). In both cases, whether verticals are included or not and whether the cant angle is at 102 or 120 degrees, the differences are typically small and depend on the azimuthal angle to the observer. Since the verticals are included in the N2A configuration, the baseline vertical was included in the "best" configuration here. Based on test results, the cant angle of 120 degrees was chosen for the "best" configuration. For community noise conditions, the HWB would typically have the center elevons deflected up. For this model the elevon deflection angle was limited to 5 degrees and this was also included in the "best" configuration.

Figure 19 shows the effect of the addition of the vertical surfaces compared to the clean airframe and also shown is the result for the addition of both the vertical surfaces and the deflected elevon surfaces. The elevon deflection appears to have the most impact; however, it is an increase in noise of about $0.5 \mathrm{~dB}$ mostly in downstream angles. This result is for the azimuthal angle of 90 degrees, directly over the observer. Figure 20 shows the impact at a different azimuthal angle. At an azimuthal angle of 60 degrees the verticals have a small noise reduction of no more than $1 \mathrm{~dB}$ but only at high frequencies and in the emission angles directly shielded by the vertical that is approximately 70 to 100 degrees. At this azimuthal angle, the elevon deflection has a negligible effect.

Yet another effect was included by installing acoustic liners flush with the elevon surface. This is a proof-ofconcept stage application that has shown some promise for another application to reduce community noise with an
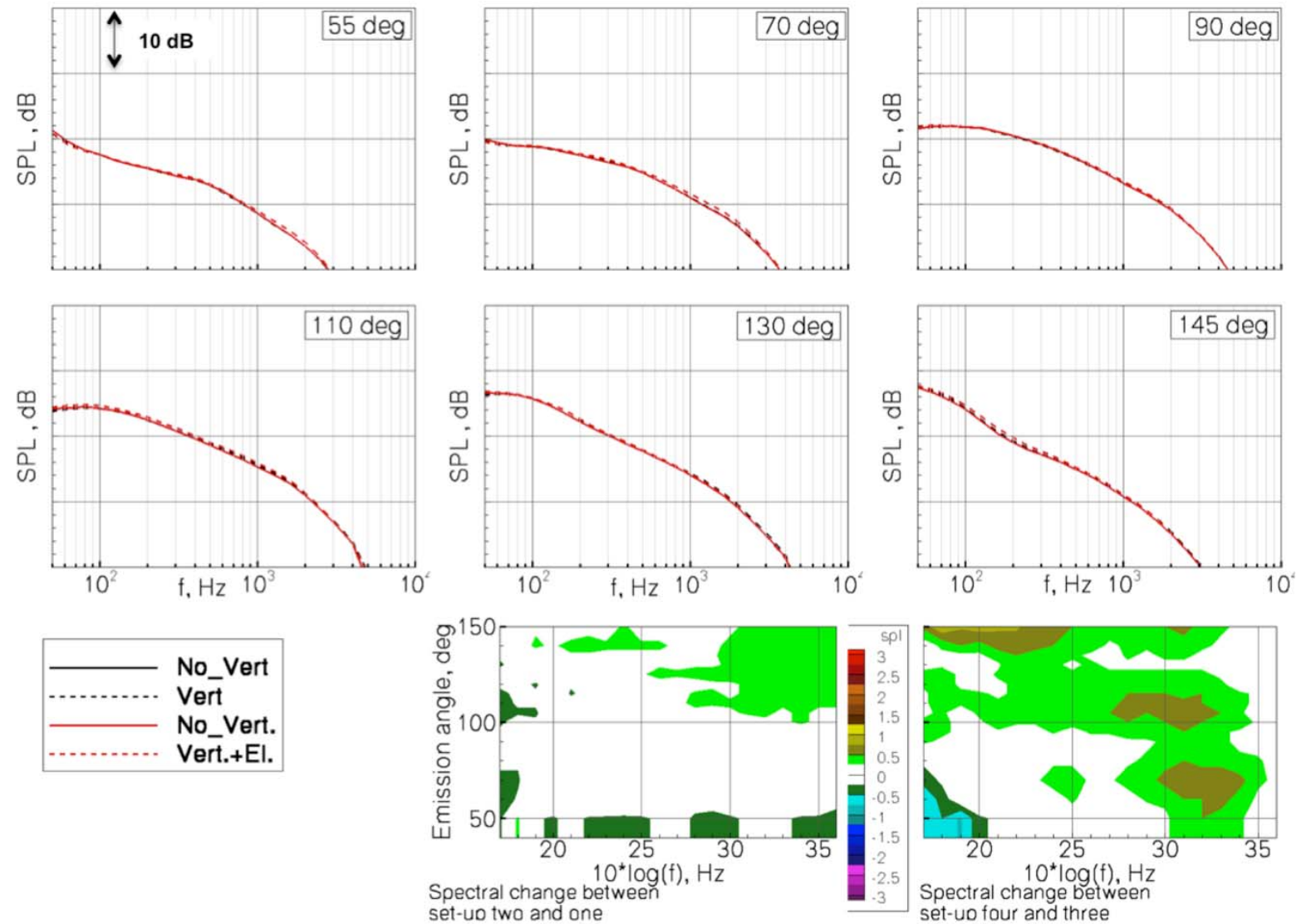

Figure 19. Effect of vertical surfaces and elevon deflection for the F8 nozzle installed at 2.17D upstream of trailing edge. Azimuthal angle of 90 degrees (using nomenclature of figure 4), directly underneath nozzle and airframe. Full scale, sideline gas condition, and $M_{T}=0.24$. 

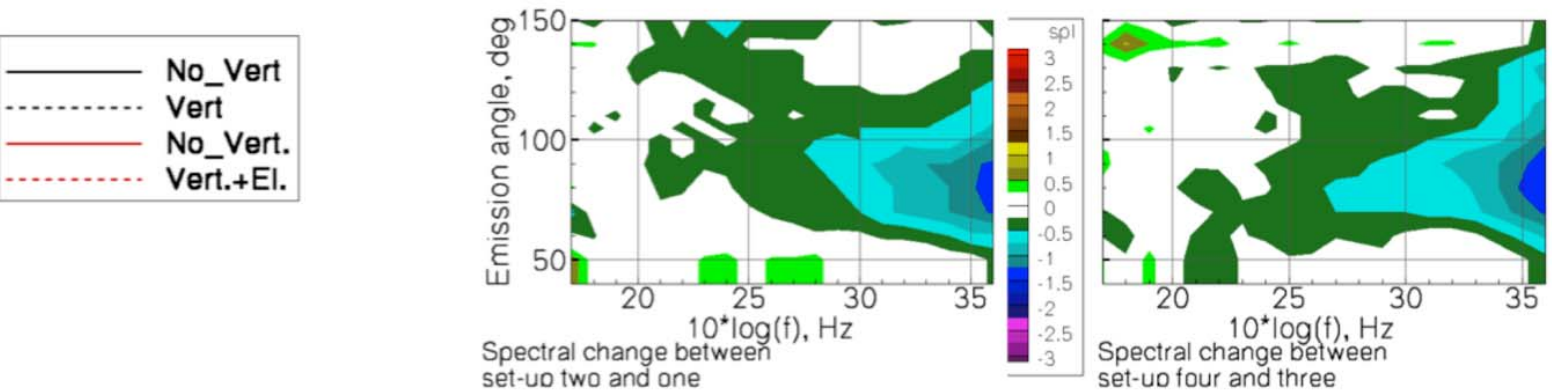

Figure 20. Effect of vertical surfaces and elevon deflection of up 5 degrees with the F8 nozzle installed at 2.17D. Azimuthal angle of 60 degrees (using nomenclature of figure 4). Full scale, sideline gas condition, and $M_{T}=0.24$.

open rotor noise source ${ }^{18}$. What was shown for the open rotor noise source was that the acoustic liners on the elevons did reduce community noise presumably by absorbing source noise propagating around the trailing edge. The same acoustic liners designed for an open rotor application were applied here for jet noise and are, therefore, not optimized. The logic was that the external acoustic liners on the elevon may have some impact on the far field noise since the F8 nozzle has moved peak jet noise sources upstream to the nozzle exit region. In fact, the acoustic liner did have a very small effect and may be worth additional study and future development.

While the additional airframe effects were minor, they were included in "best" and final configuration together with the F8 nozzle. This "best" configuration is shown in Figure 21. The final results are shown next on an installed, jet noise component EPNL dB basis. Figure 22 shows the jet EPNL $\mathrm{dB}$ as a function of X/D relative to the level of the isolated nozzle $(X / D=-1)$ at the azimuthal angle of 90 degrees directly overhead. Four nozzle configurations are shown including the baseline F1 on the clean airframe (no verticals, no elevon deflection, and no acoustic liner similar to shown in Figure 5), F3 on the clean airframe, and then F8 on the clean airframe and F8 with the additional airframe effects or the "best" configuration. As stated before, both F8 and F3 are competitive and the difference here is small. The "best" configuration includes more airframe effects that are, at this azimuthal angle, slightly detrimental to noise.

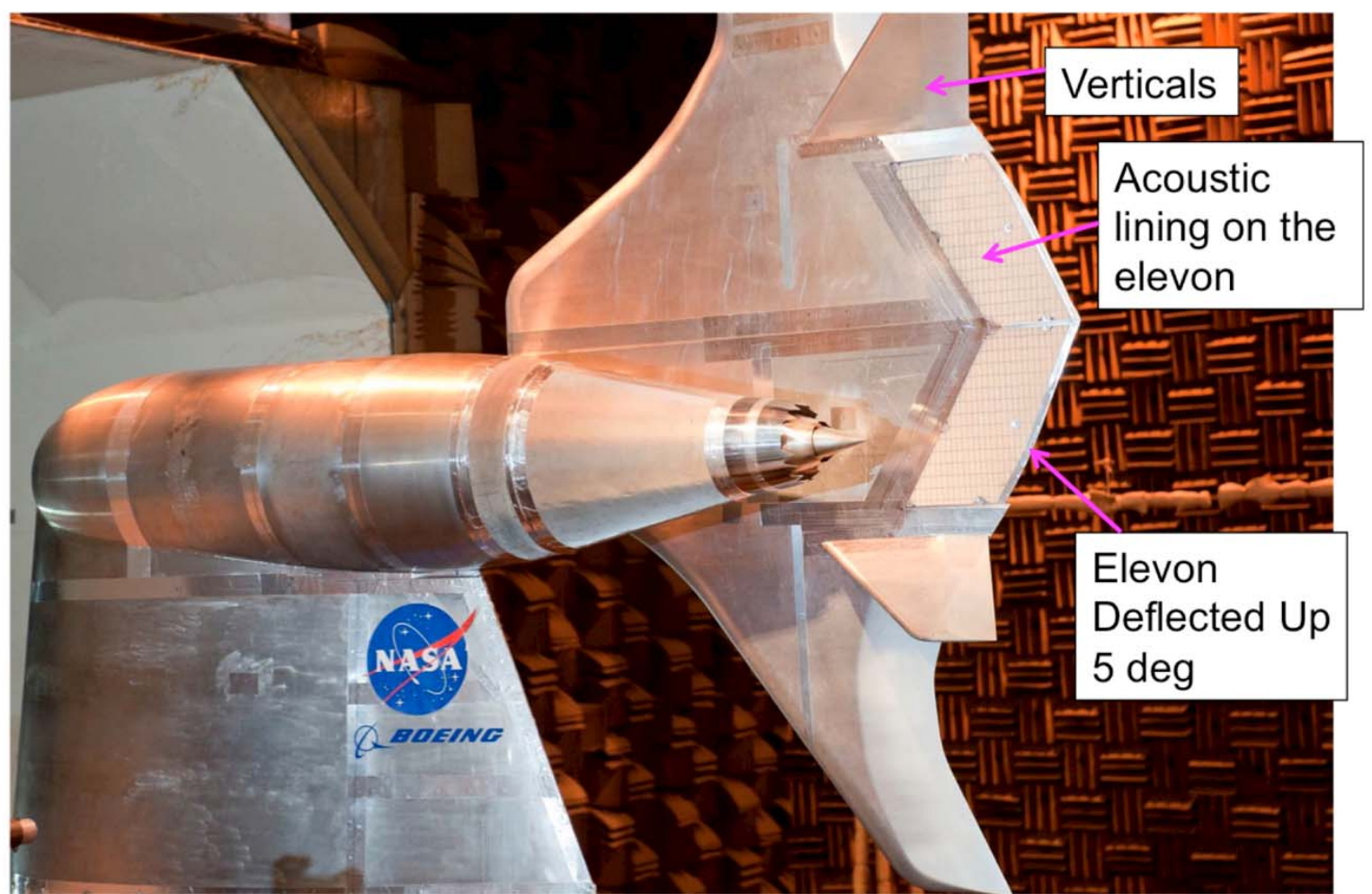

Figure 21. Photograph of the $F 8$ nozzle at $X / D=2.17 \mathrm{D}$ with vertical surfaces, elevons deflected at +5 degrees, and acoustic liners on the elevon surfaces. This is the "best" configuration of Figures 22 and 23. 


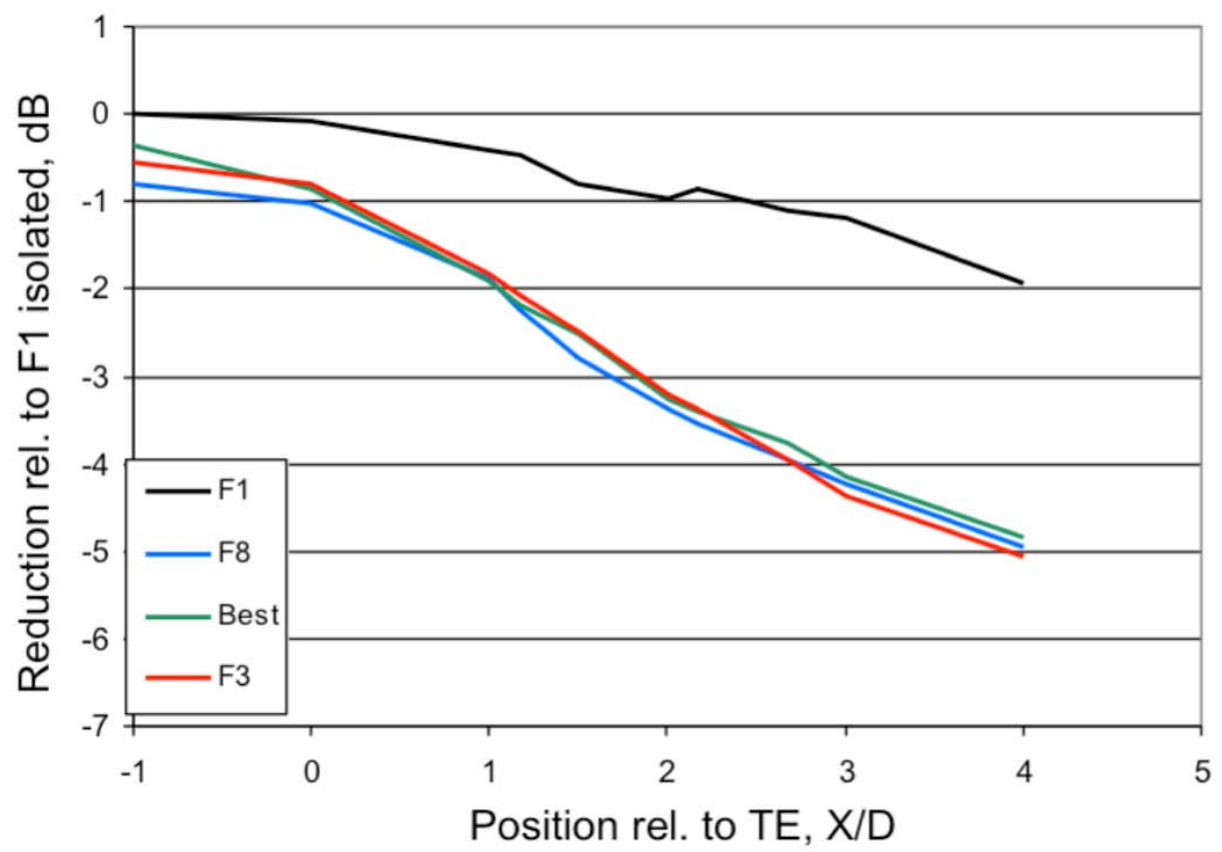

Figure 22. Jet noise EPNL dB reduction relative to the baseline $F 1$ nozzle as a function of $\mathrm{X} / \mathrm{D}$ location on the airframe, for the F8 and F3 nozzle (clean airframe) and for the F8 nozzle with vertical surfaces, elevons deflected at 5 degrees, and elevon acoustic liner effects included (best overall configuration). Azimuthal angle of 90 degree (see Figure 4), directly underneath the nozzle and airframe. Full scale, sideline gas condition, and $\mathrm{M}_{\mathrm{T}}=\mathbf{0 . 2 4}$.

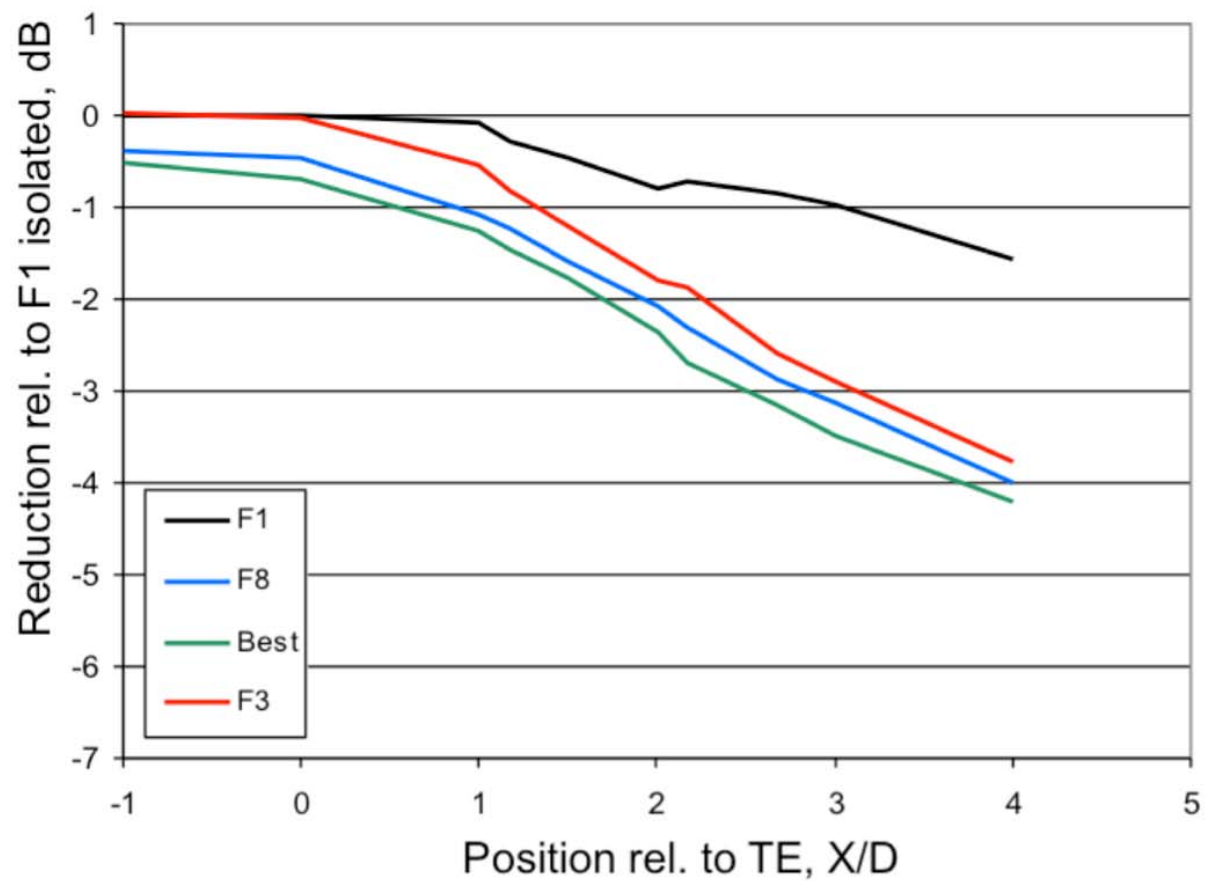

Figure 23. Jet noise EPNL dB reduction relative to the baseline F1 nozzle as a function of X/D location on the airframe, for the F8 and F3 nozzle (clean airframe) and for the F8 nozzle with vertical surfaces, elevons deflected at 5 degrees, and elevon acoustic liner effects included (best overall configuration). Azimuthal angle of 60 degree (see Figure 4). Full scale, sideline gas condition, and $M_{T}=0.24$. 
Figure 23 shows the results for the same four configurations now at the azimuthal angle of 60 degrees, an angle more representative for sideline conditions. Here the F8 is clearly better than the F3 and the additional effects of the "best" configuration do produce a small additional noise reduction.

In sum, using appropriate conditions, the "best" nozzle achieved over 6.5 EPNdB of reduction (including the elevon acoustic liners) relative to the F1 baseline by combining the sideline and cutback certification conditions. This is remarkable when compared to the $7.5 \mathrm{EPNdB}$ reduction achieved equivalently for the BPR 7 nozzle of the prior study ${ }^{12}$ with its much higher overall source levels (see Figure 12). With best available information at the time, the noise reduction achieved by the F8 for the installed jet noise component was projected to be more than sufficient to meet the noise goal for the upcoming NASA HWB 14 by 22 Foot Subsonic Tunnel aeroacoustic experiment.

\section{E. Nozzle Performance Assessment and Final Design}

The LSAF jet engine simulator has a six-component balance incorporated into it. The balance provides forces and moments based on three coordinate directions of axial, normal, and side. The balance forces were calibrated prior to the test by applying a known force in small increments from zero lbs to a force level exceeding the maximum force expected during the test. The calibration was also done in reverse starting with the maximum force and downward to zero force to document hysteresis effects, if any.

Nozzle thrust was determined by computing the magnitude of the thrust vector using the balance measurements of the axial, normal, and side forces. A nozzle velocity coefficient was determined using the thrust indicated by the balance, the ideal velocity, and the measured weight flow. The nozzle discharge coefficient was computed from the ratio of actual mass flow to ideal mass flow. The actual mass flow was measured by a venturi flowmeter and the ideal mass flow was calculated based on ideal gas law empirical relationships.

Nozzle performance data was acquired throughout the test campaign to understand the impact of configuration changes on engine thrust and fuel burn. The chevrons designed for this test created a small suppression on the nozzle discharge coefficient that was compensated for by increasing the nozzle area by small amounts, approximately $2 \%$. The effect on fuel burn was assessed to be small and of the order of 0.05 to $0.1 \%$.

At this point, the F8 nozzle had been selected as the best nozzle to achieve the necessary noise reduction and at nozzle performance that was essentially equivalent to the baseline nozzle. A final step was required to fabricate the nozzle for use in the upcoming NASA HWB 14 by 22 Foot Subsonic Tunnel high fidelity aeroacoustic experiment. For this step, the design of the F8 was adjusted in three ways. First, the scale was adjusted from $6.2 \%$ to $5.8 \%$. Second, the chevrons on the $\mathrm{C} 2$ core had a large blank for the pylon ( $\mathrm{C} 2$ had been used both with and without a pylon). Since the F8 would not use a pylon, the chevron design was adjusted some to fill in the blank. Third, based on the performance assessment, the area was adjusted very slightly to provide a closer match to the baseline. With these adjustments, Boeing fabricated and delivered the HWB noise reduction nozzle, the F8N, for use on the NASA Compact Jet Engine Simulator as part of the HWB aeroacoustic test. A photograph of the F8N is shown in Figure 24 installed on the CJES in the NASA Langley Jet Noise Laboratory during checkout testing in late 2012.

\section{Conclusions}

The propulsion airframe aeroacoustic installation effects for a bypass ratio 10 jet nozzle and a simplified HWB airframe were studied in a $6.2 \%$ scale integrated experiment in the Boeing LSAF. Prior findings ${ }^{12}$ at a lower bypass ratio of 7 were extended to this higher bypass ratio. The overall objective of this work was to design the best overall nozzle for the bypass ratio 10 nozzle of the HWB N2A concept. A crucial part of this study was to understand the installation effects that influence total jet noise reduction including shielding as part of a low noise HWB aircraft concept. The basic strategy of the prior work at bypass ratio 7 is still valid, namely to produce a nozzle design that achieves the most low frequency reduction without accompanying increases in the high frequency range, move the peak jet noise sources upstream as much as possible for more effective shielding, and finally to minimize any adverse installation effects from additional features of the airframe. Starting with the baseline round conventional bypass ratio 10 nozzle, the technologies considered included chevrons of two major design types, immersion of the chevrons, the pylon effect from a standard pylon, airframe vertical control surfaces, airframe elevon deflection angle, and acoustic liners flush in the elevon.

Building on to prior work ${ }^{12}$ both fan chevrons that were uniform circumferentially and T-fan chevrons that were asymmetrical circumferentially were tested. Both types were tested with and without a standard pylon to further understand the pylon effect. Similar to the findings at bypass ratio 7, the T-fan chevron was found to be the better overall design for this application. In general, the uniform chevrons produced too much of the high frequency 
increase while the T-fan showed even small decreases in the key downstream angles. At bypass ratio 10, chevrons were shown to move peak noise sources upstream to the vicinity of the nozzle to a lesser extent than found for lower bypass ratio nozzles. Lower mixed jet velocities as a function of higher bypass ratio are already moving jet sources upstream lessening the additional impact from chevrons. The immersion of the chevrons is a key parameter and has been increased for shielding applications compared to what is beneficial for an isolated application; this is because the high frequency increase that usually accompanies increased immersion can be shielded. Designs in this study that increased further the immersion were found to be counterproductive indicating the upper bound may have been found for this application. The orientation was also the same with the longer chevrons of the asymmetrical design opposite to the airframe and the observers at the ground location. The pylon effect was found to be significantly diminished at bypass ratio 10 compared to at lower bypass ratios and did not have an overall beneficial effect either isolated or shielded.

Significant noise reduction was possible combining the low frequency reduction from the chevrons and the shielding effectiveness from upstream peak source re-distribution and the aft shielding area at the nominal design location of 2.17 fan diameters upstream of the trailing edge. The effects from the additional airframe features were overall limited. The vertical surfaces produced noise reduction of up to $1 \mathrm{~dB}$ but only in a limited polar and azimuthal angle range. Elevon deflection also was dependent on azimuthal angle of the observer and was also small in impact, although the deflection was only 5 degrees. This effect is likely to increase for higher elevon deflection angles. A new concept of acoustic liners imbedded in the elevon was also tested with limited impact, although the design was not optimized for this jet noise application. Further work would need to be done on this noise reduction concept.

When adding the sideline and the cutback points, over $6.5 \mathrm{EPNdB}$ of jet noise reduction was achieved by the installed best overall nozzle relative to the isolated baseline nozzle. The best overall nozzle includes the T-fan chevron oriented with the longer chevrons in the asymmetrical pattern away from the airframe and ground observer locations, and a core chevron that is essentially a uniform design circumferentially. This nozzle has been selected and fabricated for the upcoming high fidelity aeroacoustic characterization experiment of the N2A HWB concept in the NASA Langley 14 by 22 Foot Subsonic Tunnel beginning in late 2012.

Using the high fidelity F8N nozzle, the upcoming N2A high fidelity aeroacoustic experiment is designed to add the additional effects from two jet nozzles (instead of the single jet used in the current study), angle of attack, and a greater range of elevon deflection angle.

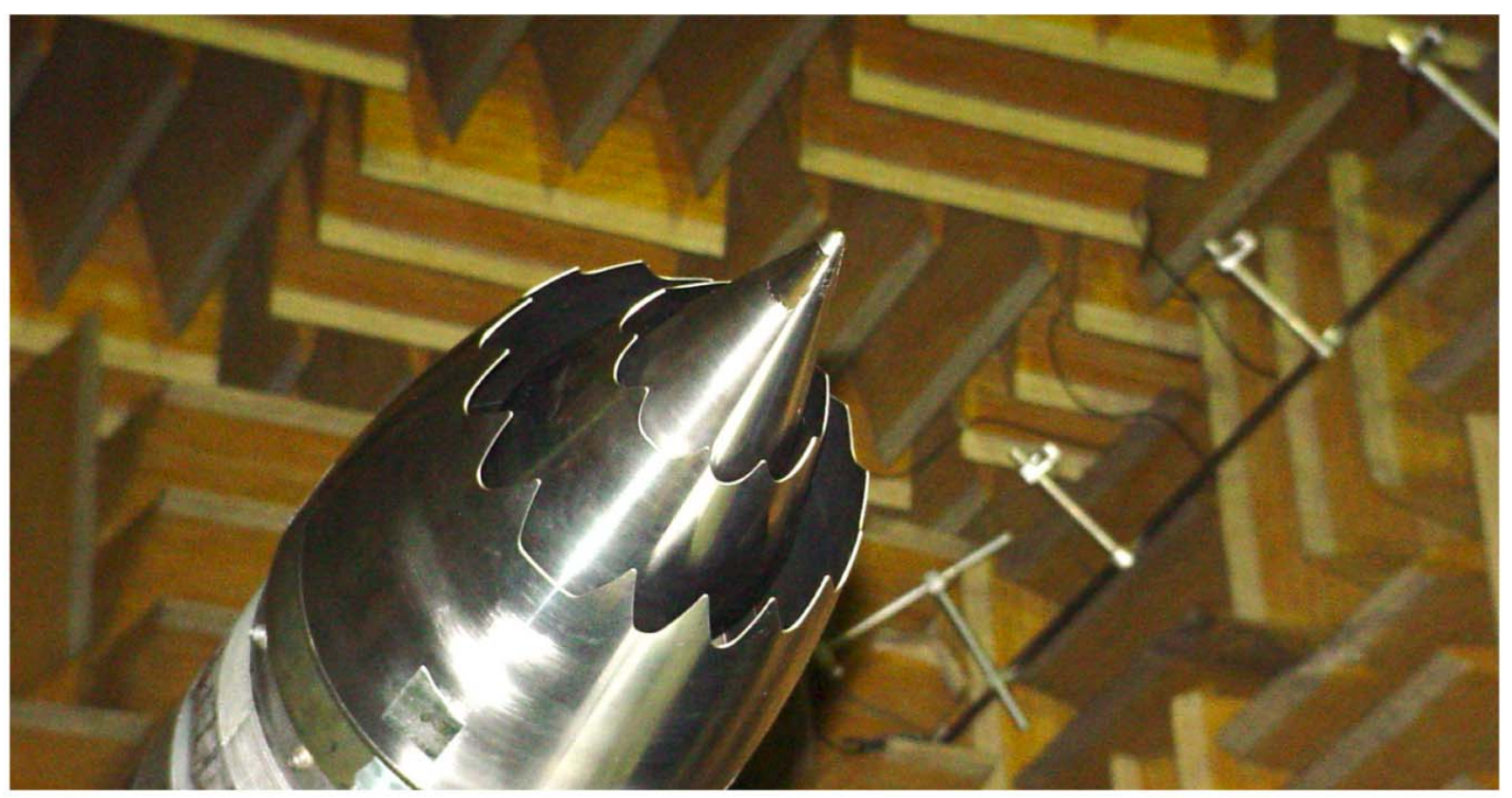

Figure 24. The best overall nozzle design, the F8N, installed on the Compact Jet Engine Simulator in the NASA Langley Jet Noise Laboratory. 


\section{Acknowledgements}

The authors would like to thank the Environmentally Responsible Aviation Project for the funding of this research. The Propulsion Groups of Boeing Research and Technology and of Boeing Commercial Airplane are thanked for their design of and subsequent performance assessment of the nozzle configurations, specifically, John Croxford, Juan Cajigas, Gary Galerne and Dan Tomkins are thanked for their contributions. The design team including Scott Nilson and Curt Berquist produced high quality hardware and met an aggressive schedule. In addition, the entire Boeing ANP group and the LSAF test group led by Steve Underbrink and test engineer Robyn Jones are thanked for the very productive execution of the PAA Nozzle Configuration test in November-December of 2011.

\section{References}

${ }^{1}$ Collier, F.S., "Environmentally Responsible Aviation (ERA) Project," presentation at the Third NASA Fundamental Aeronautics Program Annual Meeting, September 29-October 1, 2009, Atlanta, Georgia.

${ }^{2}$ Hill, G.A. and Thomas, R.H., "Challenges and Opportunities for Noise Reduction Through Advanced Aircraft Propulsion Airframe Integration and Configurations," presented at the $8^{\text {th }}$ CEAS Workshop on Aeroacoustics of New Aircraft and Engine Configurations, Budapest, Hungary, Nov. 11-12, 2004.

${ }^{3}$ Martens, S., "Jet Noise Reduction Technology Development at GE Aircraft Engines." ICAS Paper 842, presented at the International Council of the Aeronautical Sciences, Toronto, Canada, September, 2002.

${ }^{4}$ Thomas, R., and Kinzie, K., "Jet-Pylon Interaction of High Bypass Ratio Separate Flow Nozzle Configurations," AIAA Paper No. 2004-2827.

${ }^{5}$ Massey, S., Thomas, R., Abdol-Hamid, K., and Elmiligui, A., "Computational and Experimental Flow Field Analyses of Separate Flow Chevron Nozzles and Pylon Interaction," AIAA Paper 2003-3212.

${ }^{6}$ Hunter. C., and Thomas, R., "Development of a Jet Noise Prediction Method for Installed Jet Configurations," AIAA Paper 2003-3169.

${ }^{7}$ Hunter, C.A., Thomas, R.H., Abdol-Hamid, K.S., Pao, S.P., Elmiligui, A.A., and Massey, S.J., "Computational Analysis of the Flow and Acoustic Effects of Jet-Pylon Interaction," AIAA Paper No. 2005-3083.

${ }^{8}$ Mengle, V., Elkoby, R., Brusniak, L., and Thomas, R., "Reducing Propulsion Airframe Aeroacoustic Interactions with Uniquely Tailored Chevrons: Part 1. Isolated Nozzles,” AIAA Paper No. 2006-2467.

${ }^{9}$ Nesbitt, E., Mengle, V., Czech, M., Callendar, B., and Thomas, R., "Flight Test Results for Uniquely Tailored Propulsion Airframe Aeroacoustic Chevrons: Community Noise," AIAA Paper 2006-2438.

${ }^{10}$ Massey, S.J., Elmiligui, A.A., Hunter, C.A., Thomas, R.H., Pao, S.P., and Mengle, V.G., "Computational Analysis of a Chevron Nozzle Uniquely Tailored for Propulsion Airframe Aeroacoustics," AIAA Paper No. 2006-2436.

${ }^{11}$ Nesbitt, E., Brusniak, L., Underbrink, J., Lynch, D., and Martinez, M., "Effects of Chevrons on Engine Jet Noise Structure", AIAA-2007-3597.

${ }^{12}$ Czech, M.J., Thomas, R.H., and Elkoby, R., Propulsion Airframe Aeroacoustic Integration Effects of a Hybrid Wing Body Aircraft Configuration, International Journal of Aeroacoustics, Volume 11, Number 3+4, 2012, pp. 335-368.

${ }^{13}$ Thomas, R. H., Burley, C. L., and Olson, E.D., Hybrid Wing Body System Noise Assessment with Propulsion Airframe Aeroacoustic Experiments, International Journal of Aeroacoustics, Volume 11, Number 3+4, 2012, pp. 369-410.

${ }^{14}$ Gatlin, G.M., Vicroy, D.D., and Carter, M.B., "Experimental Investigation of the Low-Speed Aerodynamic Characteristics of a 5.8-Percent Scale Hybrid Wing Body Configuration," AIAA Paper 2012-2669, presented at the 30 ${ }^{\text {th }}$ AIAA Applied Aerodynamics Conference, June 25-28, 2012.

15 Kawai, R.T., "Acoustic Prediction Methodology and Test Validation for an Efficient Low-Noise Hybrid Wing Body Subsonic Transport," Final Report for NASA Contract Number NNL07AA54C, February, 25, 2011.

${ }^{16}$ Shields, F.D. and Bass, H.E., "A Study of Atmospheric Absorption of High Frequency Noise and Application to Fractional Octave Bands of Noise,” NASA Contractor Report 2760, 1976.

${ }^{17}$ Pierce, A.D., Acoustics - An Introduction to its Physical Principles and Applications, McGraw Hill, 1981.

${ }^{18}$ Czech, M.J. and Thomas, R.H., "Experimental Studies of Open Rotor Installation Effects," presentation at the AIAA $3{ }^{\text {rd }}$ Atmospheric and Space Environments Conference, June, 2011. 